San Jose State University

SJSU ScholarWorks

Master's Theses

Master's Theses and Graduate Research

Fall 2013

\title{
Spatiotemporal Variability in the Diet of Nonbreeding Brandt's Cormorant (Phalacrocorax penicillatus) in the Monterey Bay Region
}

Lisa Webb

San Jose State University

Follow this and additional works at: https://scholarworks.sjsu.edu/etd_theses

\section{Recommended Citation}

Webb, Lisa, "Spatiotemporal Variability in the Diet of Nonbreeding Brandt's Cormorant (Phalacrocorax penicillatus) in the Monterey Bay Region" (2013). Master's Theses. 4405.

DOI: https://doi.org/10.31979/etd.pgn5-rs4j

https://scholarworks.sjsu.edu/etd_theses/4405

This Thesis is brought to you for free and open access by the Master's Theses and Graduate Research at SJSU ScholarWorks. It has been accepted for inclusion in Master's Theses by an authorized administrator of SJSU ScholarWorks. For more information, please contact scholarworks@sjsu.edu. 


\author{
A Thesis \\ Presented to \\ The Faculty of the Department of Marine Science \\ San José State University
}

\author{
In Partial Fulfillment \\ of the Requirements for the Degree \\ Master of Science
}

by

Lisa Annette Webb

December 2013 
(C) 2013

Lisa Annette Webb

ALL RIGHTS RESERVED 
The Designated Thesis Committee Approves the Thesis Titled

SPATIOTEMPORAL VARIABILITY IN THE DIET OF

NONBREEDING BRANDT'S CORMORANT (PHALACROCORAX PENICILLATUS) IN THE MONTEREY BAY REGION

by

Lisa Annette Webb

APPROVED FOR THE DEPARTMENT OF MARINE SCIENCE

SAN JOSÉ STATE UNIVERSITY

December 2013

Dr. James T. Harvey Moss Landing Marine Laboratories

Dr. Gregor M. Cailliet Moss Landing Marine Laboratories

Dr. Josh Adams $\quad$ U.S. Geological Survey 


\begin{abstract}
SPATIOTEMPORAL VARIABILITY IN THE DIET OF

NONBREEDING BRANDT'S CORMORANT (PHALACROCORAX PENICILLATUS) IN THE MONTEREY BAY REGION
\end{abstract}

by Lisa Annette Webb

Brandt's Cormorant (Phalacrocorax penicillatus) diet composition was investigated using pellets $(\mathrm{n}=285)$ collected on 19 sampling days at 3 locations during the 2006-07 and 2007-08 nonbreeding seasons in the Monterey Bay region. The conventional diet method was used, and the efficacy of the all-structure technique was evaluated. Although 29 species were consumed, Northern Anchovy (Engraulis mordax) dominated the diet and Speckled Sanddab (Citharichthys stigmaeus) also was important. Few rockfishes (Sebastes spp.) and Market Squid (Doryteuthis opalescens) were consumed compared with the number consumed in previous studies in the region during the 1970s. El Niño and La Niña conditions during the study provided a unique opportunity to examine predator response. Greatest prey number and diversity occurred at locations within Monterey Bay during cooler ocean conditions, whereas the outer coast location remained unchanged. Short-term specialization was observed, but mean prey diversity indicated a generalist feeding mode. Patterns of prey number and diversity within a nonbreeding season were not consistent among locations. This study demonstrated the importance of periodic sampling at multiple locations within a region to detect spatiotemporal variability in the diet of this opportunistic generalist. 


\section{ACKNOWLEDGEMENTS}

I would like to thank my committee, Dr. James Harvey, Dr. Gregor Cailliet, and Dr. Josh Adams, for their knowledge, insight, and enthusiasm. This study benefited greatly from their guidance and review. I am also indebted to my friend and colleague, Simon Brown, for the many statistical discussions that improved this study.

Point Blue Conservation Science provided access to Año Nuevo Island and the U.S. Coast Guard granted access to the Monterey Harbor breakwater. Samples were collected under National Marine Fisheries Service Permit No. 87-1851-00 and IACUC Protocols 2003-E, F, \& G, and 2007-E, F, \& H. Thank you to the many people who assisted with sample collection.

I am grateful for the financial support I received for this study: H. Thomas Harvey Fellowship, Gerdts Fellowship, Signe Lundstrom Memorial Scholarship, Myers Oceanographic and Marine Biology Trust Grant, Packard Research and Travel Grant, and a National Science Foundation Grant (No. HRD-0802628) administered by Dr. William Head at the California State University Monterey Bay Undergraduate Research Opportunities Center (UROC). Through the UROC program I was able to mentor two incredible undergraduate interns, Erin Frolli and Chandra Baughman. Their assistance processing samples was instrumental in the completion of this project and their humor kept me going on the toughest days.

As my advisor, Dr. James Harvey provided a foundation in statistics, sampling design, critical thinking, and writing that will be useful throughout my career. He also provided numerous employment and fieldwork opportunities that enriched my time at 
Moss Landing Marine Laboratories (MLML). The outstanding faculty and staff at MLML combined with the supportive, hard-working, and fun-loving environment created a wonderful graduate school experience. I was surrounded by many bright people in the Vertebrate Ecology Lab and appreciate the comradery I found there. The good humor and distraction of many friends provided respite when needed, in particular Corinne Gibble, Kristine Williams, Ashley Neway, Rosemary Romero, Colleen Young, Erica Donnelly-Greenan, Brian Hoover, Jeremiah Brower, and Simon Brown.

Thank you to my family for understanding the commitments of graduate school and for their interest in my work. My parents, Maria and Richard Wertz, always told me that I could do anything I put my mind to and together with my sister, Tina Paradise, and her family provided constant support and enjoyable times away from school.

My husband, Jason, provided relentless encouragement before and throughout graduate school. Without him I could not have achieved this goal. I appreciate all of his time and assistance with every aspect of this study. I dedicate this thesis to him and to our daughter, Violet, whose lively spirit continues to inspire me. 


\section{TABLE OF CONTENTS}

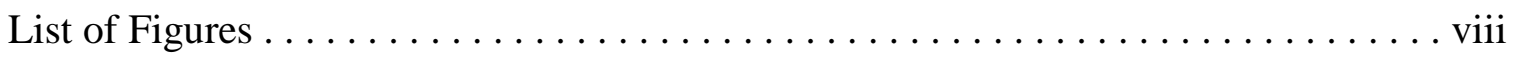

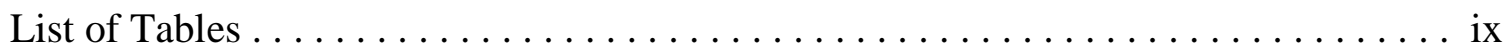

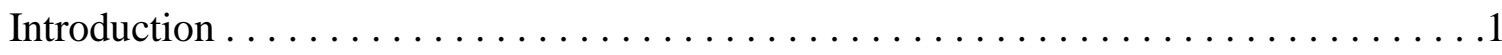

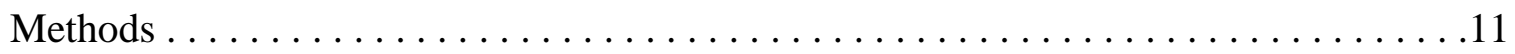

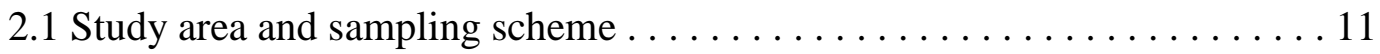

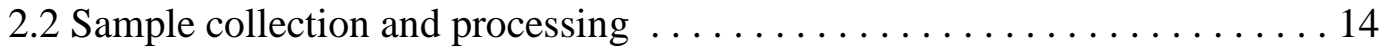

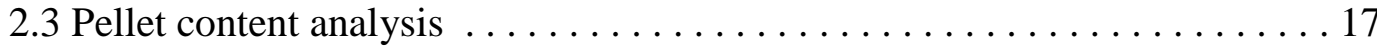

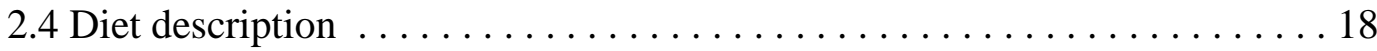

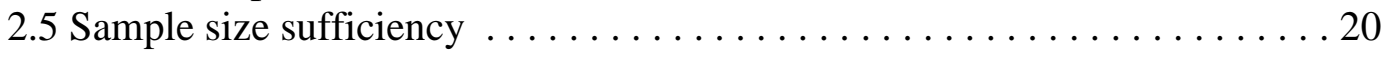

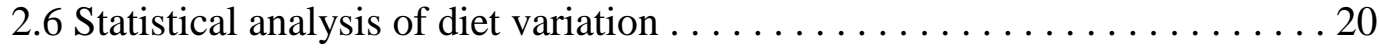

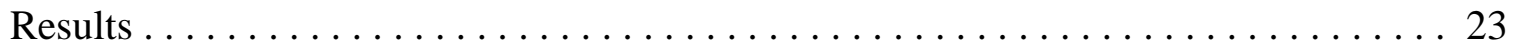

3.1 Nested sieves and efficacy of all-structure technique $\ldots \ldots \ldots \ldots \ldots 23$

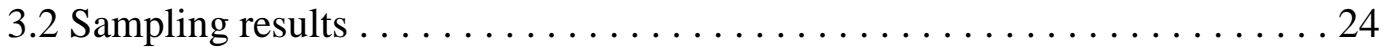

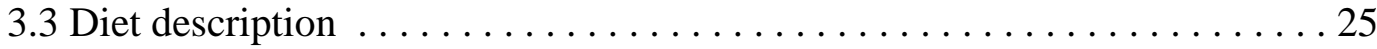

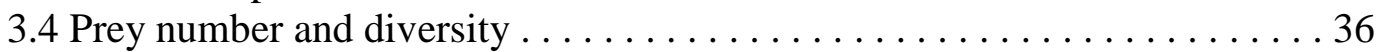

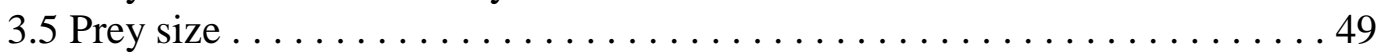

3.6 Fine-scale spatiotemporal variation . . . . . . . . . . . . . . . 49

3.7 Comparing historical and present diet composition .............. 51

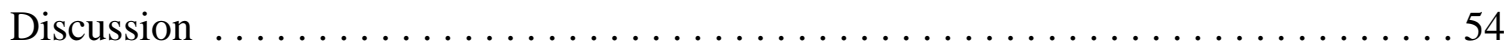

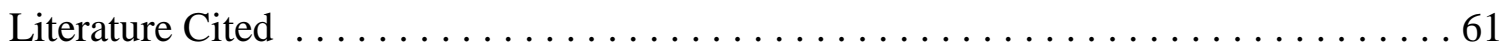




\section{LIST OF FIGURES}

Figure 1. Diet composition by percent number for past studies in central California . . . 4

Figure 2. The Monterey Bay region study area with sampling locations $\ldots \ldots \ldots \ldots 12$

Figure 3. Sampling scheme during 2006-07 and 2007-08 nonbreeding seasons . . . . . 14

Figure 4. Precision (SE) of resampled means for percent prey-specific number for

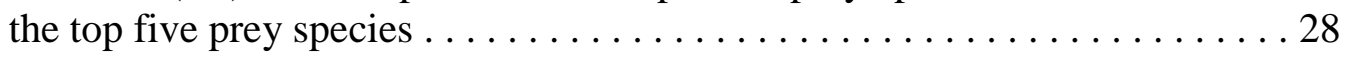

Figure 5. Cumulative number of prey categories with $95 \%$ confidence intervals for the diet during the 2006-07 and 2007-08 nonbreeding seasons . . . . . . . 29

Figure 6 . Feeding strategy diagrams by location and nonbreeding season $\ldots \ldots \ldots 32$

Figure 7. Boxplots of prey number by time period and location during the 2006-07

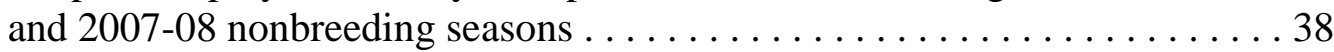

Figure 8 . Boxplots of prey diversity by time period and location during the 2006-07

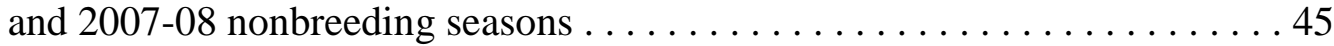

Figure 9. Fine-scale spatiotemporal variation in mean percent number among sampling days during the 2006-07 and 2007-08 nonbreeding seasons . . . . 50

Figure 10. Nonmetric multidimensional scaling ordination comparing spatiotemporal variation in diet composition $(\% \mathrm{~N})$ among sampling days . . 51

Figure 11. Diet composition by percent number $(\% \mathrm{~N})$ for past studies in central

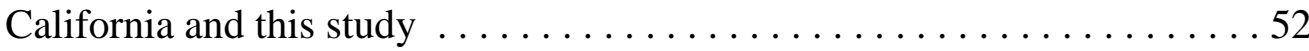

Figure 12. Nonmetric multidimensional scaling ordination comparing overall diet composition $(\% \mathrm{~N})$ among historic studies and this study $\ldots \ldots \ldots \ldots 3$ 


\section{LIST OF TABLES}

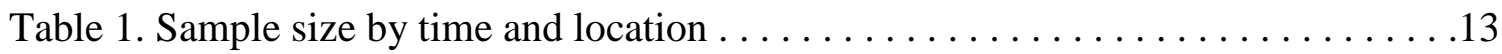

Table 2. Taxonomic classification, common name, and code for prey species . . . . . 26

Table 3. Diet composition by mean percent number, mean percent prey-specific number, and frequency of occurrence by nonbreeding season . . . . . . . 27

Table 4. Diet composition by mean percent number, mean percent prey-specific number, and frequency of occurrence by location . . . . . . . . . . . . 30

Table 5. Diet composition by location during the 2006-07 nonbreeding season . . . . . 33

Table 6. Diet composition by location during the $2007-08$ nonbreeding season . . . . . 34

Table 7. ANOVA of prey number among time periods and between locations

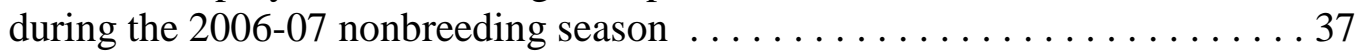

Table 8. ANOVA of prey number among time periods and locations during the 2007-08 nonbreeding season . . . . . . . . . . . . . . . . . . 39

Table 9. ANOVA of prey number between 2006-07 and 2007-08 nonbreeding seasons, among time periods within nonbreeding seasons, and between

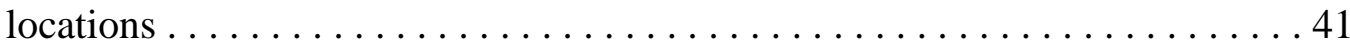

Table 10. Mean and range for number of prey categories and Shannon-Wiener diversity index by time period and location $\ldots \ldots \ldots \ldots \ldots \ldots \ldots$

Table 11. ANOVA of prey diversity among time periods and between locations during the $2006-07$ nonbreeding season . . . . . . . . . . . . . 44

Table 12. ANOVA of prey diversity among time periods and locations during the $2007-08$ nonbreeding season $\ldots \ldots \ldots \ldots \ldots \ldots \ldots \ldots \ldots \ldots \ldots \ldots \ldots \ldots \ldots \ldots$

Table 13. ANOVA of prey diversity between 2006-07 and 2007-08 nonbreeding seasons, among time periods within nonbreeding seasons, and between

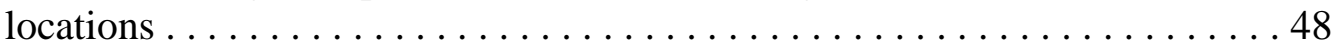

Table 14. Range of estimated standard lengths of fishes consumed . . . . . . . . 49 


\section{INTRODUCTION}

The Brandt's Cormorant (Phalacrocorax penicillatus) is the most abundant locally nesting seabird in the Monterey Bay region of central California. Four new colonies formed and grew rapidly from 1989 to the mid-2000s (Carter et al. 1992, Bechaver et al. 2013). As a generalist predator (Cutler 1983) occupying a middle-toupper trophic position in the nearshore marine food web (Ainley et al. 1995), the species consumes young-of-the-year and juvenile-age classes of fishes and, to a lesser extent, squid (Sydeman et al. 2001). Given their reliance on the nearshore environment (Wallace and Wallace 1998), year-round occurrence, restricted foraging range within $10 \mathrm{~km}$ of the shore (Briggs et al. 1987), and consumption of approximately $20 \%$ of their body mass per day (Ancel et al. 1997), there is potential for Brandt's Cormorants to extract large numbers of prey from the nearshore environment in the Monterey Bay region, yet little is known about their diet there.

Brandt's Cormorants are medium-sized, foot-propelled pursuit divers with a stiff, rudder like tail, an elongated neck, and a long, hooked bill (Boekelheide et al. 1990). They are visual predators (Hubbs et al. 1970) and Henkel (2006) reported they occurred more often in the clearest water available in Monterey Bay despite greater productivity in more turbid waters. The wettable plumage of cormorants appears to reduce buoyancy (Owre 1967), possibly allowing them to descend faster and remain at depth with less effort compared with other diving seabirds; however, no time-depth recorders have been placed on this species. They counter buoyancy at shallow depths by controlling body tilt 
with their tail (Ribak et al. 2004). These characteristics promote maneuverability while foraging underwater and allow them to feed from the surface to the bottom.

A review of Brandt's Cormorant diet throughout their range indicated nearly equal proportion of schooling and non-schooling prey (Ainley et al. 1981). Foraging depths inferred from habitat of prey consumed were $12 \%$ taken from surface to middepth, $47 \%$ from mid-depth to the bottom, $29 \%$ on the bottom, and $12 \%$ cryptic species on the bottom. When foraging in Monterey Bay during winter, prey were taken in a variety of substrates with $36 \%$ in flat sand or mud, $32 \%$ in rocky reef, $28 \%$ in the water column from surface to mid-depth, and $4 \%$ in flat area near rocks.

From 1979 to 2011, there were 18 Brandt's Cormorant colonies in the Monterey Bay region with maximum abundance of approximately 20,500 breeding birds in 2006 (Bechaver et al. 2013; USFWS, unpublished data). Three colonies were located north of the bay on the outer coast and 5 colonies were within Monterey Bay. The remaining 10 colonies were located south of the bay on the Monterey Peninsula outer coast, the largest of which is Bird Island, averaging approximately 1,900 breeding birds (Bechaver et al. 2013).

Recent Brandt's Cormorant population growth and expansion may be related to changing prey resources in the region and warrants investigation. Año Nuevo Island is located north of Monterey Bay on the outer coast and has been identified as important seabird habitat in California (Briggs et al. 1987). Brandt's Cormorants began nesting on Año Nuevo Island in 1989 (Carter et al. 1992) and increased to nearly 5,000 breeding birds by 2006 (USFWS, unpublished data). Nesting began just outside the northern 
opening to Monterey Bay between Terrace Pt. and Pt. Santa Cruz in 1996 (Hebshi 1998) and averaged 80 breeding birds from 2003 to 2006 (Bechaver et al. 2013). Nesting within Monterey Bay was first recorded in the mid-1990s and increased to nearly 2,500 breeding birds at 5 colonies by 2006 (Bechaver et al. 2013). Three of the 5 colonies were located at or near Monterey Harbor, where diverse habitat may provide abundant prey resources. Nesting began in the central bay in 2004 (personal observation) at Moss Landing Harbor (<200 breeding birds) and in northern Monterey Bay in 2005 at Seacliff Cement Ship (< 500 breeding birds; Bechaver et al. 2013). It is unknown if Brandt's Cormorants in the Monterey Bay region forage in Elkhorn Slough, situated just east of the Moss Landing Harbor, where fish spawning and nursery habitat are located and abundant and diverse fishes occur seasonally (Yoklavich et al. 1991).

The two previous Brandt's Cormorant diet studies in Monterey Bay were both during the 1970s and sampled the nonbreeding season (Baltz and Morejohn 1977, Talent 1984; Fig. 1). Results differed somewhat, potentially because each study had small sample size $(\mathrm{n} \leq 11)$ and collected birds in different habitats (inshore versus offshore) during different years. Rockfishes (Sebastes spp.) and Pacific Sanddab (Citharichthys sordidus) were the two main prey during the 1970-71 nonbreeding season and also occurred during the 1974-75 nonbreeding season; however, Northern Anchovy (Engraulis mordax) and Market Squid (Doryteuthis opalescens) also were important in 1974-75. Since then, a substantial decrease in abundance of juvenile rockfishes occurred during the 1990s in the central California Current with only partial recovery as of the early 2000s (Mills et al. 2007). Commercial Market Squid landings in Monterey Bay 
decreased substantially beginning in 2005 (CDFG 2009) indicating decreased abundance.

The change in dominant ichthyofauna correlate to cyclical changes in sea surface temperature that are the result of either the Pacific Decadal Oscillation on a longer time scale or the El Niño Southern Oscillation on a shorter time scale (Chavez et al. 2003). Determining present diet composition will aid in our understanding of how a major avian predator in the region responds to a decrease of multiple important prey resources and will provide important information about Monterey Bay food web dynamics.

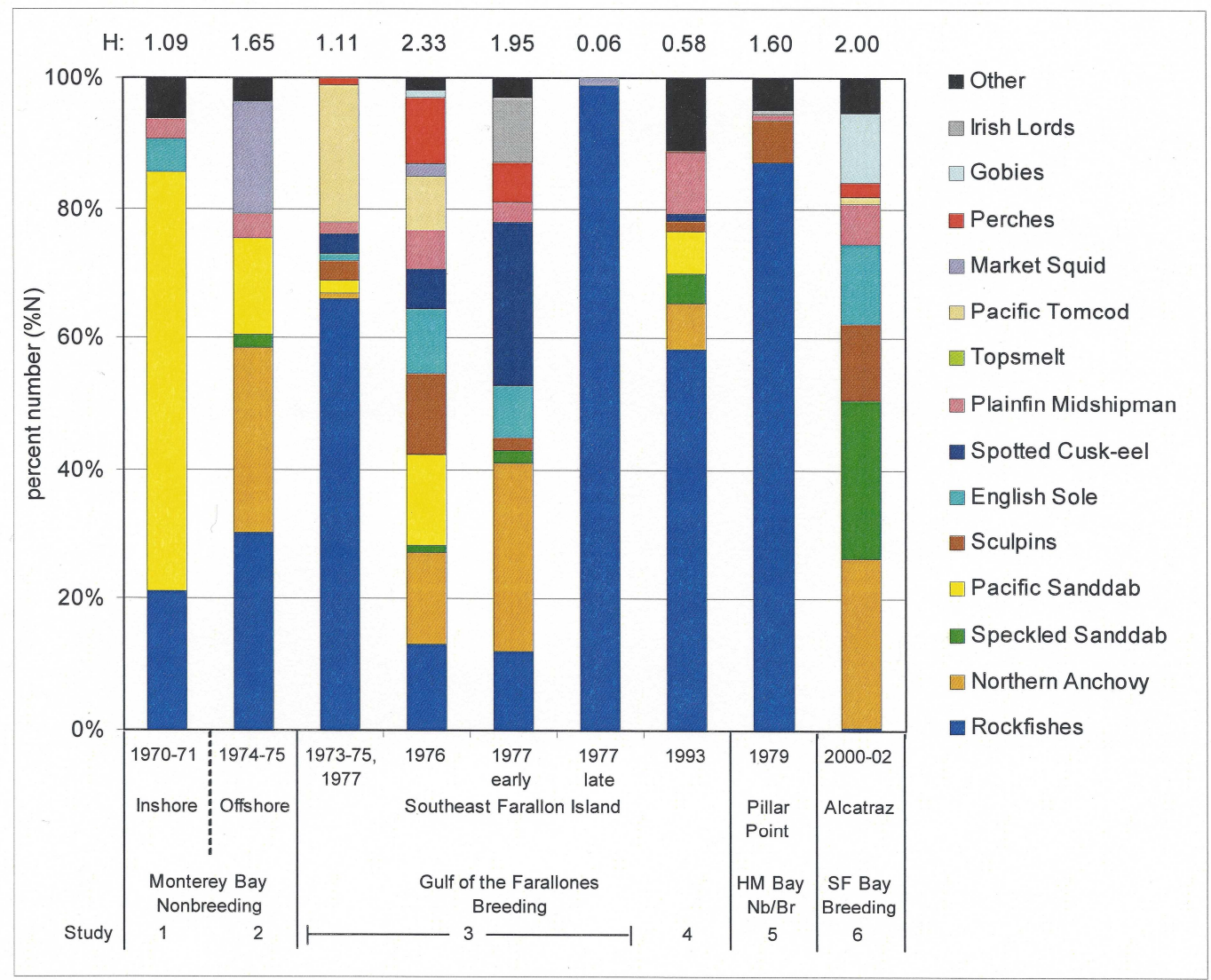

Figure 1. Brandt's Cormorant diet composition by percent number $(\% \mathrm{~N})$ for past studies in central California. Prey species comprising less than $5.0 \%$ were combined into category "Other". Shannon-Wiener diversity index $(\mathrm{H})$ is provided above each bar and time, location, region, and breeding status below each bar. Data are from 1) Talent 1984, 2) Baltz and Morejohn 1977, 3) Ainley et al. 1990, 4) Sydeman et al. 1997, 5) Cutler 1983, and 6) Yakich 2005. 
Brandt's Cormorants are capable of short-term specialization on abundant prey but also may diversify their diet with changing ocean conditions (Baltz and Morejohn 1977, Cutler 1983, Talent 1984, Ainley et al. 1990, Sydeman et al. 1997, Yakich 2005; Fig. 1). For example, at Southeast Farallon Island where diet was investigated for many breeding seasons during the 1970s, rockfishes made up $99 \%$ of the diet by number late in the 1977 breeding season, yet during the 1976 breeding season when ocean conditions were anomalously warm, rockfishes were only $13 \%$ of the diet by number with the remaining 87\% split among 12 fish species and Market Squid (Ainley et al. 1990).

There also is some evidence that Brandt's Cormorant foraging behavior and diet vary as a function of habitat available near the colony or roost, likely because of their limited foraging range (Briggs et al. 1987, Hebshi 1998). Hebshi (1998) observed Brandt's Cormorants foraging in northern Monterey Bay from Soquel Pt. to Davenport Pt. in shallow kelp forest and sandy substrate habitat. The most important factors determining where cormorants foraged were 1) proximity to colony or roost, 2) amount of kelp canopy cover, 3) presence of rocky substrate, and 4) less long-term exposure to wind and heavy seas. Diet at Alcatraz Island in San Francisco Bay included appreciable numbers of Bay Goby (Lepidogobius lepidus) (Yakich 2005; Fig. 1) when Bay Goby was abundant (Fish et al. 2011). Similarly, appreciable numbers of Market Squid were reported only in the diet of birds collected offshore in Monterey Bay (Baltz and Morejohn 1977; Fig. 1), and Monterey Bay has an important Market Squid spawning ground (McInnis and Broenkow 1978). Overall, these findings are consistent with localized foraging and opportunistic predation. 
Variability in seasonal distribution of Brandt's Cormorants in the Monterey Bay region may be important when interpreting diet variation. Brandt's Cormorants occur in Monterey Bay throughout the year (Baltz and Morejohn 1977, Briggs et al. 1987), but they do not use the area homogeneously. During breeding, April through August, nesting cormorants act as central place foragers because they must return to their colonies to maintain nests, incubate eggs, and provision young (Boekelheide et al. 1990). During the nonbreeding season, September through March, individuals remain within $25 \mathrm{~km}$ of any acceptable roosting location (Briggs et al. 1987) because they must return to shore to rest, thermoregulate, and dry their feathers. At-sea strip transect survey data in Monterey Bay from 1997 to 2005 indicated a clumped distribution during breeding with more dense concentrations of Brandt's Cormorants near colonies at Monterey Harbor and Moss Landing Harbor than elsewhere in the bay. During winter the observed distribution in the bay was more uniform (D. Croll, unpublished data). Thus, movements are less constrained during the nonbreeding season and may be regional (>50 km) during the course of a few days.

Intraseasonal forcing on Brandt's Cormorant behavior and diet are linked to seasonal oceanographic influences that affect prey availability and should be accounted for when sampling cormorant diet. Greater marine productivity occurs in Monterey Bay during summer after northwest winds generate coastal upwelling north of the bay at Point Año Nuevo. Cold, nutrient rich waters are advected into the bay via cyclonic surface circulation (Breaker and Broenkow 1994, Rosenfeld et al. 1994, Paduan and Rosenfeld 1996). Pulses of primary productivity also occur during spring, and occasionally fall, 
making the region productive for much of the year but less so during winter (November through January; Pennington and Chavez 2000). The timing of the Brandt's Cormorant breeding season is aligned with peak ocean productivity and abundant prey (Boekelheide and Ainley 1989) that occur during the upwelling season (spring and summer). The nonbreeding season corresponds to the non-upwelling season which includes postbreeding (September and October), winter (November to January), and prebreeding (February and March). Dominant fishes in Monterey Bay vary seasonally (Cailliet et al. 1979). Rockfishes and Market Squid occurred in moderate numbers and greater frequency in summer. During winter Northern Anchovy occurred in greater numbers and frequency and Pacific Sanddab and Speckled Sanddab (Citharichthys stigmaeus) occurred frequently but in lesser numbers.

Brandt's Cormorant diet also may differ by location according to diversity in the nearshore habitats of the Monterey Bay region. Areas with greater habitat diversity are more likely to have a greater diversity of fishes because fish species generally occur in one or a few habitat types. Habitat used by various families and species of fish can be characterized by depth, distance from shore, marine zones (estuarine, subtidal, neritic, pelagic), distance from the bottom, and substrate type (Miller and Lea 1972). Año Nuevo Island is $1 \mathrm{~km}$ from shore, exposed on the outer coast, and $11 \mathrm{~km}$ from a canyon that extends in from the shelf break. Año Nuevo Bay has shallow depths of less than $25 \mathrm{~m}$ and primarily sandy substrate with a few rocky outcrops and some beds of giant kelp (Macrocystis pyrifera) (Henkel and Harvey 2006). Within Monterey Bay, the opening at the north and south has exposed, rocky coast with abundant kelp forests. In central 
Monterey Bay there are large areas with sand or mud substrate. Elkhorn Slough, the third largest estuary in California, is located just inland of the Moss Landing Harbor. Monterey Bay is bisected by the vast Monterey Submarine Canyon (Shepard 1973). Several other canyons extend in from the shelf break in the region. Pelagic water is closest to Moss Landing Harbor and nearly equidistant from Año Nuevo Island and Monterey Harbor.

Collecting diet samples at multiple locations is necessary for examining spatial variation in the region. Three of four colonies that were more recently colonized were accessible to sample and provided representation of northern (Año Nuevo Island), central (Moss Landing Harbor), and southern (Monterey Harbor) portions of the Monterey Bay region. Año Nuevo Island is approximately $60 \mathrm{~km}$ from Moss Landing Harbor and 70 km from Monterey Harbor. Moss Landing Harbor and Monterey Harbor are approximately $25 \mathrm{~km}$ apart. The diverse habitats of the Monterey Bay region are represented by these three locations.

Many methods are available to study seabird diet (Barrett et al. 2007). Cormorants produce one pellet per day containing prey remains from the prior $24 \mathrm{~h}$ (Duffy and Laurenson 1983, Jobling and Breiby 1986, Zijlstra and Van Eerden 1995). Some considered cormorant pellets equivalent to stomach samples (Jordán 1959, Ainley et al. 1981), and the daily consumption derived from pellets matched energetic demands in a few studies (Voslamber 1988, Dirksen et al. 1995). Most fish otoliths, cephalopod beaks, and other prey hard parts contained in cormorant pellets have enough structure to determine species (Duffy and Laurenson 1983). 
Collecting pellets at colony or roost locations is well suited for a study with the aim of addressing fine-scale spatiotemporal variation because birds do not have to be killed to obtain the larger sample sizes required, the diet sample is not biased by the habitat the bird is collected in (Hubbs et al. 1970), and the diet is not time-averaged over months like many other dietary methods (Barrett et al. 2007). Increased sampling frequency is important because at a regional scale Brandt's Cormorants may alter their foraging habitat on the order of days (Hubbs et al. 1970), especially during the nonbreeding season when they are less constrained. Prey remains in pellets can be identified and enumerated with unparalleled taxonomic resolution at minimal cost.

Some have criticized using pellets to reconstruct the diet because otoliths from small size classes of fishes, and otoliths of certain fish species with fragile otoliths may be disproportionately digested, thereby leading to their underestimation (Duffy and Laurenson 1983, Duffy and Jackson 1986, Jobling and Breiby 1986, Johnstone et al. 1990, Casaux et al. 1995, Zijlstra and Van Eerden 1995). These potential biases are consistent through time; therefore, pellets do provide an index of diet. Overall, pellets are useful for answering broad spatiotemporal questions such as comparing diet between seasons or years (Ainley et al. 1981, Duffy and Laurenson 1983, Duffy and Jackson 1986, Barrett et al. 1990, Harris and Wanless 1993, Sapoznikow et al. 2009). In pinniped diet studies, using the all-structure technique rather than just otoliths has improved prey detection (Tollit et al. 2003), but this technique has not yet been evaluated for seabird pellets. 
The objectives of this study were to 1) evaluate the efficacy of nested sieves and the all-structure technique for increasing prey detection, 2) quantify the 2006-07 and 2007-08 nonbreeding season diet, 3) estimate prey size, 4) examine fine-scale spatiotemporal differences in diet composition within and between nonbreeding seasons, and 5) examine temporal differences in diet composition between the present diet and historical diet and the possible influence of relative abundance of prey and oceanographic conditions.

I expected that using nested sieves and the all-structure technique would increase prey detection for a few species compared with using a single sieve and identifying only fish otoliths and cephalopod beaks. I hypothesized that prey number and diversity would be greater in the nonbreeding season with cooler, more productive oceanographic conditions. I predicted that prey number would be lesser and prey diversity greater during winter (November through January) compared with postbreeding (September and October) and prebreeding (February and March) because oceanographic conditions would be less productive in Monterey Bay during winter (Pennington and Chavez 2000) and Brandt's Cormorants have less constrained movements at that time (Briggs et al. 1987). I expected prey number and prey diversity would be greater at locations within the bay (Moss Landing Harbor and Monterey Harbor) compared with the location outside the bay (Año Nuevo Island) because in a single day Brandt's Cormorants foraging within Monterey Bay would encounter more habitat types. I expected that regardless of nonbreeding season, prey diversity would be in accordance with habitat diversity near each location: greatest at Monterey Harbor, intermediate at Moss Landing Harbor, and 
least at Año Nuevo Island. I expected diet composition to primarily be explained by location because of general differences in nearby habitat and secondarily explained by time period within the nonbreeding season because of differential availability of abundant prey. I expected the present diet to be different from historical diet because of major changes in dominant ichthyofauna, particularly that there would be lesser numbers of rockfishes and Market Squid.

\section{METHODS}

\subsection{Study area and sampling scheme}

The study was conducted in central California and included Monterey Bay and surrounding coastal areas (36 $50^{\prime} \mathrm{N}, 122^{\circ} 05^{\prime} \mathrm{W}$; Fig. 2). Regurgitated pellets were collected once or twice per month at roosting locations at Año Nuevo Island, Moss Landing Harbor, and Monterey Harbor on 19 randomly selected days from approximately mid-September through March during the 2006-07 and 2007-08 nonbreeding seasons. Monterey Harbor was sampled only during 2007-08 (Table 1 and Fig. 3). Breeding activities were monitored so that disturbance was minimized. Sampling began in the fall when all chicks had fledged, and sampling was ceased in the spring once courtship behaviors were observed. 


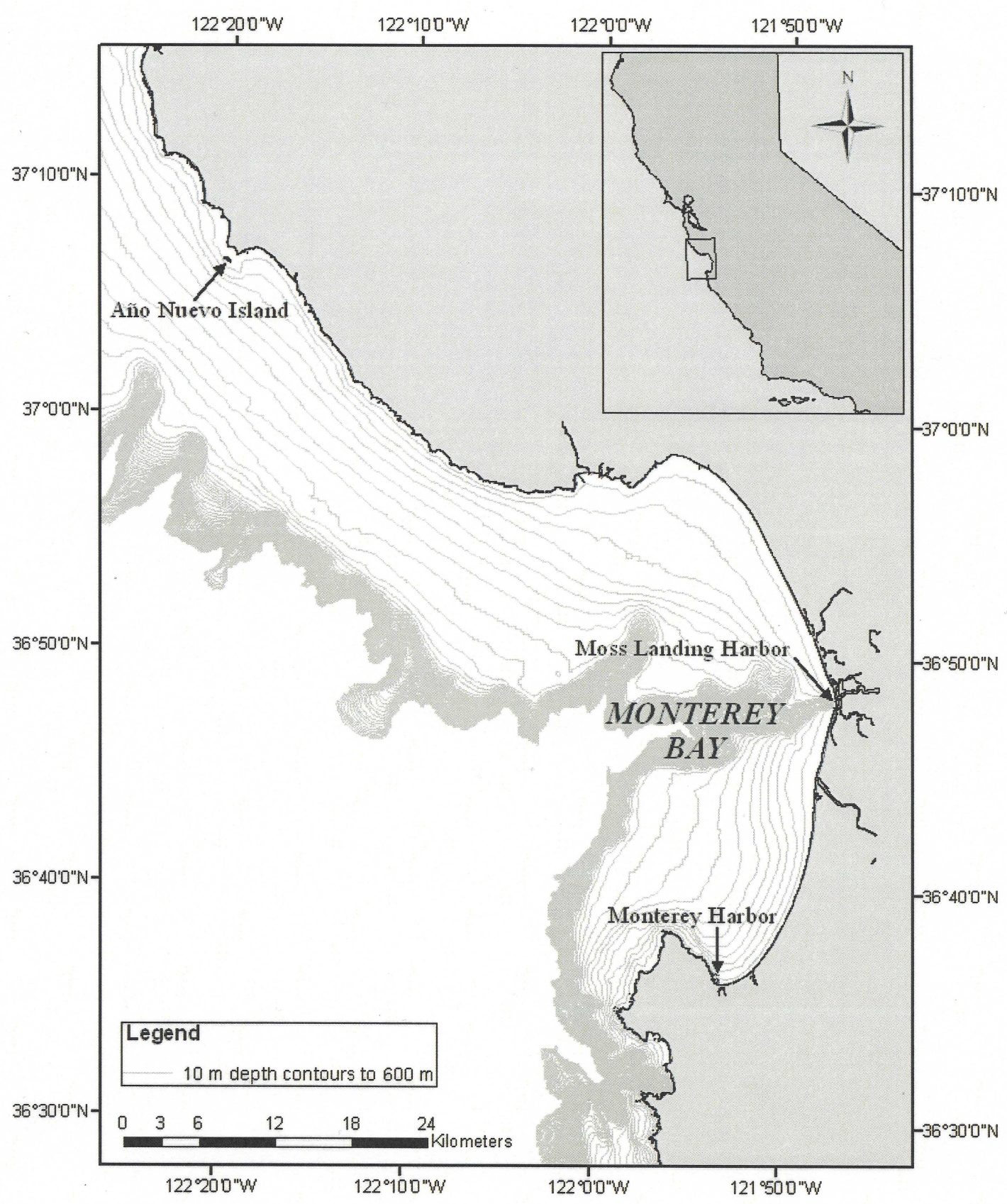

Figure 2. The Monterey Bay region study area and 3 sampling locations. Depth contours are shown every $10 \mathrm{~m}$ to $600 \mathrm{~m}$ depth, depicting the continental shelf and canyon features. Map inset indicates the location of the Monterey Bay region in central California. 
Table 1. Sample size by time and location.

\begin{tabular}{clr}
\hline \hline Time & \multicolumn{1}{c}{ Location } & \multicolumn{1}{c}{$\mathrm{n}$} \\
\hline $09 / 21 / 06$ & Moss Landing Harbor & 10 \\
$09 / 26 / 06$ & Año Nuevo Island & 12 \\
$12 / 18 / 06$ & Moss Landing Harbor & 11 \\
$12 / 19 / 06$ & Año Nuevo Island & 9 \\
$02 / 22 / 07$ & Moss Landing Harbor & 13 \\
$03 / 02 / 07$ & Año Nuevo Island & 12 \\
$09 / 25 / 07$ & Año Nuevo Island & 12 \\
$09 / 28 / 07$ & Moss Landing Harbor & 15 \\
$10 / 19 / 07$ & Monterey Harbor & 13 \\
$11 / 09 / 07$ & Moss Landing Harbor & 14 \\
$11 / 15 / 07$ & Año Nuevo Island & 12 \\
$11 / 29 / 07$ & Monterey Harbor & 14 \\
$12 / 21 / 07$ & Moss Landing Harbor & 8 \\
$12 / 26 / 07$ & Monterey Harbor & 13 \\
$01 / 17 / 08$ & Año Nuevo Island & 11 \\
$02 / 20 / 08$ & Moss Landing Harbor & 13 \\
$03 / 10 / 08$ & Montcrey Harbor & 15 \\
$03 / 24 / 08$ & Año Nuevo Island & 14 \\
$03 / 26 / 08$ & Moss Landing Harbor & 8 \\
$2006-07$ & Año Nuevo Island & 33 \\
$2006-07$ & Moss Landing Harbor & 34 \\
$2007-08$ & Año Nuevo Island & 49 \\
$2007-08$ & Moss Landing Harbor & 58 \\
$2007-08$ & Monterey Harbor & 55 \\
All & Año Nuevo Island & 82 \\
A1l & Moss Landing Harbor & 92 \\
All & Monterey Harbor & 55 \\
$2006-07$ & All & 67 \\
$2007-08$ & All & 162 \\
All & All & 229 \\
\hline & & \\
\hline
\end{tabular}




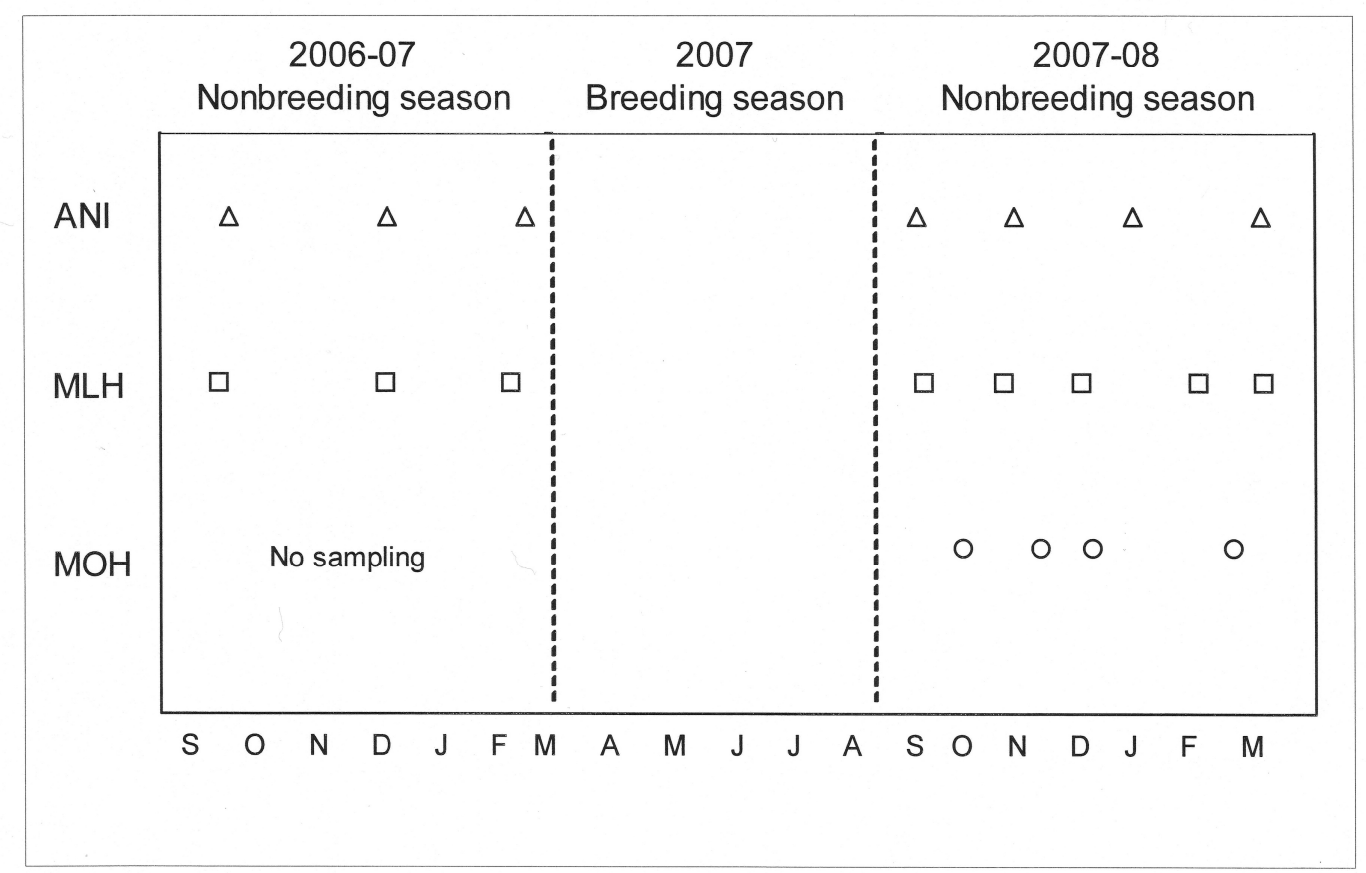

Figure 3. Sampling scheme with 19 sampling days during 2006-07 and 2007-08 nonbreeding seasons at 3 locations: Año Nuevo Island (ANI, triangles), Moss Landing Harbor (MLH, squares), and Monterey Harbor (MOH, circles).

\subsection{Sample collection and processing}

Locations were observed before sample collection to determine where Brandt's Cormorants roosted. On sampling days pellets were collected shortly after sunrise because cormorants cast pellets at daybreak (Ainley et al. 1981, Zijlstra and Van Eerden 1995), bird abundance decreases after sunrise as birds leave to forage (Ainley et al. 1981), and gulls may scavenge cormorant pellets (Spear 1993). Fresh pellets are clear to yellow and mucilaginous. Older pellets can be distinguished because they harden and become darker (Ainley et al. 1981). Only fresh, intact pellets with no tears in the outer covering were collected. Gull pellets were avoided because they have no outer covering 
and are primarily composed of fish bones. Pellets were not collected in areas where Double-crested Cormorants ( $P$. auritus) or Pelagic Cormorants (P. pelagicus) roost. All seabirds were counted before flushing, and counts were evaluated throughout the study period for rapid decreases that may have been attributed to disturbance from collecting pellets. Up to 50 pellets were collected per sampling day. Each pellet was placed in an individual storage bag, labeled, and frozen until later processing.

In the laboratory, each pellet was thawed in a separate jar with water and a small amount of detergent to slow digestive enzyme activity and limit further erosion of prey remains. After an initial 30-min soak the pellet was carefully opened using forceps. The jar was gently agitated to ensure thorough mixing of the detergent solution with the prey remains and then left to soak overnight. A $500 \mu \mathrm{m}$ sieve was used to sort all samples. For each sampling day, approximately $20 \%$ of samples were sorted with nested $500 \mu \mathrm{m}$ and $250 \mu \mathrm{m}$ sieves to assess if identifiable prey remains were missed. Each sieve was examined for prey remains first with the naked eye and then again at $6.7 \mathrm{X}$ to $40 \mathrm{X}$ magnification with a zoom stereo microscope. Prey remains were stored for later identification, enumeration, and measurement. Hard parts such as fish otoliths, fish bones, and invertebrate carapace fragments were stored dry in petri dishes (Lance et al. 2001). Other tissues such as fish and cephalopod eye lenses, cephalopod beaks, and other chitinous invertebrate parts were stored in vials containing $40 \%$ isopropyl alcohol (Baltz and Morejohn 1977, Lance et al. 2001).

During identification and enumeration, all prey remains were examined at $6.7 \mathrm{X}$ to 40X magnification with a zoom stereo microscope. Images were taken as needed to 
provide documentation of characteristics of the prey remains using a custom-mounted, digital color microscope camera with 12-bit color depth and 1,600 × 1,200 pixel resolution (Scion CFW-1612C digital color camera, Scion Corporation, Frederick, MD, USA). Prey remains were identified using guides (Schmitt 1921, Cannon 1987), scientific literature (Allis 1909, Chapman 1944a, Chapman 1944b, Iverson and Pinkas 1971, Liem 1986, Hansel 1988, Hayashi and Kim 1999, Harvey et al. 2000, Gobalet et al. 2004), reference collections (Moss Landing Marine Laboratories, Point Blue Conservation Science [formerly Point Reyes Bird Observatory], University of California at Santa Cruz, and NOAA Fisheries Service Fisheries Ecology Division), and consultation with taxonomic experts (Joe Bizzarro at Moss Landing Marine Laboratories and Cristie Boone at University of California at Santa Cruz).

Some prey remains could be resolved only to family or genus because of erosion or lack of unique morphological characteristics, and they were combined into prey categories (e.g., rockfishes, sculpins, perches). However, in most instances prey remains could be resolved to species (e.g., Black Rockfish [Sebastes melanops], Pacific Staghorn Sculpin [Leptocottus armatus], Pile Surfperch [Rhacochilus vacca]). Thus, an effort was made to identify all prey remains to the lowest taxonomic level and prey categories were used only in cases of uncertainty. Because prey remains were not all identified to species, the term prey category will be used hereafter. 


\subsection{Pellet content analysis}

Prey remains were enumerated using the food habits protocol outlined by Lance et al. (2001). The number and size of single and paired structures (e.g., atlas vertebra, right and left sagittal fish otoliths, upper and lower cephalopod beaks, small and large sculpin preopercles) were used to conservatively estimate the minimum number of individuals (MNI). Prey that could not be enumerated were noted as present or absent and conservatively contributed to prey number (e.g., presence of perch teeth or pieces of perch pharyngeal plate indicated 1 perch). The all-structure technique was evaluated by noting other fish remains such as eye lenses, premaxilla, dentary, preopercle, pharyngeal plate, teeth, atlas, axis, hypural vertebra, and other vertebrae (Tollit et al. 2003). This was extended to invertebrates by using cephalopod eye lenses or chitinous exoskeleton fragments that indicated their number or presence. Other materials such as parasites, sediment, plant material, and small rocks were noted.

Fish otolith erosion was graded following Tollit et al. (1997): Grade 1 (least erosion), Grade 2 (moderate erosion), and Grade 3 (heavy erosion). Grade 1 otoliths have a distinct sulcus and features such as clear lobations. They were measured to the nearest $0.01 \mathrm{~mm}$ using a digital caliper. Fish length was estimated only for Grade 1 otoliths using published regression equations that relate otolith length to fish length (Harvey et al. 2000), and the mean fish length was determined by species. Cephalopod beaks were too worn to be measured for size estimation. 


\subsection{Diet description}

The prey number was standardized to a percentage on a per pellet basis. Then mean prey-specific number (Amundsen et al. 1996), frequency of occurrence, and mean percent number (Hyslop 1980) metrics were calculated as follows:

(1) mean percent prey-specific number: $\quad \% P N_{i}=\frac{\sum_{j=1}^{n} \% N_{i j}}{n_{i}} \times 100$

(2) percent frequency of occurrence:

$$
\% F O_{i}=\frac{n_{i}}{n} \times 100
$$

(3) mean percent number:

$$
\% N_{i}=\frac{\sum_{j=1}^{n} \% N_{i j}}{n} \times 100
$$

where $N_{i j}$ is the proportion of prey $i$ in an individual sample $j, n_{i}$ is the number of samples containing prey $i$, and $n$ is the total number of samples. These metrics were calculated for each nonbreeding season, sampling location, and each combination of nonbreeding season and location. The mean prey-specific number refers to the average proportion consumed of each prey $i$, but only when prey $i$ was consumed. When mean prey-specific number is multiplied by percent frequency of occurrence, or the proportion of samples containing prey $i$, the result is mean percent number. Mean percent number is a compound index that summarizes overall importance of prey $i$ in the diet (Brown et al. 2012). 
Differences in the diet for a location and nonbreeding season were deciphered and visualized using a feeding strategy diagram that incorporates $\% \mathrm{PN}$ and $\% \mathrm{FO}$ metrics to indicate if, as a group of individuals, the feeding strategy of the predator was a specialist $(\% \mathrm{PN}>50 \%)$ or generalist $(\% \mathrm{PN}<50 \%$; Costello 1990). Taking this concept a step further, Amundsen et al. (1996) defined the inter- and intra-individual components of niche width. When a prey was consumed frequently in great number, the prey was defined as dominant in the diet $(\% \mathrm{FO}>50$ and $\% \mathrm{PN}>50 \%)$. Conversely, when a prey was infrequently consumed in lesser numbers the prey was defined as rare in the diet $(\% \mathrm{FO}<50 \%$ and $\% \mathrm{PN}<50 \%)$. Infrequently consumed prey eaten in great number $(\% \mathrm{FO}<50 \%$ and $\% \mathrm{PN}>50 \%)$ indicated only some individuals were specialists. Frequently consumed prey eaten in lesser number $(\% \mathrm{FO}>50 \%$ and $\% \mathrm{PN}<50 \%)$ indicated many individuals were generalists.

Lastly, diet diversity was calculated using Shannon's entropy, $H$, also known as Shannon-Wiener diversity index (Shannon 1948):

(4) Shannon-Wiener diversity index: $\quad H=-\sum_{i=1}^{q} p_{i} \ln p_{i}$

where $p_{i}$ is the proportion of individuals belonging to the $\mathrm{i}^{\text {th }}$ species in the dataset and $q$ is the total number of prey species. 


\subsection{Sample size sufficiency}

To determine if there were sufficient samples to precisely estimate the \%PN metric for the top five prey species, a custom program (R-Project Organization) was written to randomly resample $\% \mathrm{PN}$ values and calculate mean $\% \mathrm{PN}$ and standard error (SE) for increasing sample size (J. Harvey, personal communication). Adequate sample size for a precise \% PN estimate was deemed to be where the variability (SE of \% PN) stabilized.

To determine if enough pellets had been sampled to sufficiently characterize the number of prey categories in the diet, a cumulative prey curve (Ferry and Cailliet 1996) was generated for each nonbreeding season (EstimateS, Version 8.2., R. K. Colwell, http://viceroy.eeb.uconn.edu/estimates). The estimated number of unique prey categories and associated $95 \%$ confidence intervals were plotted against the cumulative number of pellets examined. Sufficient sample size was determined to be where the linear regression of the ultimate four samples became asymptotic $(\mathrm{b} \leq 0.05)$ (Bizzarro et al. 2007).

\subsection{Statistical analysis of diet variation}

Analysis of variance (ANOVA) was used to test for the effect of three fixed factors on prey number and prey diversity: nonbreeding season (2006-07 and 2007-08), time period within a nonbreeding season (postbreeding, winter, and prebreeding), and location (Año Nuevo Island, Moss Landing Harbor, and Monterey Harbor). Interdependence among factors was assessed with ANOVA interaction terms. Only two 
nonbreeding seasons were selected for examination so this was considered a fixed factor. Postbreeding, winter, and prebreeding periods are biologically meaningful times during the nonbreeding season and all of those times were examined, so time period was considered a fixed factor. Location was considered a fixed factor because the three locations examined were of interest because of recent colonizations and habitat differences that were hypothesized to affect the diet.

The study design was not orthogonal because Monterey Harbor was sampled only during 2007-08; therefore, a separate two-way ANOVA was used to test location and time period for each nonbreeding season. A three-way ANOVA was used to test season, time period, and location, but only for Año Nuevo Island and Moss Landing Harbor that were sampled during both nonbreeding seasons. Samples containing no prey were excluded from the analysis and random samples were dropped until sample size per cell was equal. Before testing, the data were $\log$ transformed by $\ln (x+1)$ to meet assumptions of normality and equal variance and then the data were backtransformed to report means.

The assemblage of species consumed by a predator form a multivariate data matrix containing columns of univariate prey variables with interdependencies and rows that are independent observation vectors, in this case, pellet samples (Legendre and Legendre 1998). When one prey occurs in great number because it is abundant in the environment and it is readily encountered and consumed, other prey numbers are lesser in the diet because the predator has a limit to the amount of food it can consume at any one time. Similarly, prey species encountered in a particular habitat type are more likely to 
be similar to one another (e.g., consuming several species of benthic fishes in an area with rocky substrate). Thus, prey variables often contain a large number of zeros making them greatly skewed. These data properties do not conform to parametric statistics with underlying assumptions of normality and equal variance and simple transformations cannot solve all of the underlying problems.

Ordination techniques project multivariate data into a smaller number of dimensions with limited loss of information by using a dissimilarity measure to make pairwise comparisons of the samples, producing a sample-by-sample data matrix (Legendre and Legendre 1998). The interpretation of absence of two prey species, or double-zeros, is ambiguous because multiple scenarios could lead to that result. Data sets with many double-zeros are not well suited for the metric dissimilarity measures that are required in many ordination methods because they are attributed as similarities when this may not be the case. This interpretation can result in an illogical conclusion known as the species abundance paradox: two sites without any species in common may be represented in ordination space with less distance between them than another pair of sites with species in common. Nonmetric multidimensional scaling (NMDS) is an unconstrained ordination technique that allows the use of dissimilarity measures appropriate for ecological data sets. The Bray-Curtis dissimilarity measure was used with NMDS ordination to compare fine-scale spatiotemporal diet variation among the 19 sampling days in this study and to compare historical Brandt's Cormorant diet data to season and location data subsets in this study. 


\section{RESULTS}

\subsection{Nested sieves and efficacy of all-structure technique}

Fish remains were mostly otoliths, lenses, and degraded vertebrae, but perch (Embiotocidae) pharyngeal plate pieces and teeth, and sculpin preopercles also were found. Fish otoliths provided the greatest MNI estimate with the best taxonomic resolution. Within samples, perch pharyngeal teeth or pharyngeal plate pieces were always accompanied by perch otoliths. Similarly, even when various sizes of sculpin preopercles were considered to produce the greatest possible MNI by sculpin preopercles, it rarely produced a greater MNI than sculpin otoliths.

Invertebrate remains included squid and octopus beaks, crab carapace and claws, mollusk shells, polychaete jaws, and shrimp and isopod exoskeleton and appendage parts, all of which are composed of chitinous material that resist digestion. Thus, invertebrate remains potentially were from secondary prey, consumed first by a fish that was then eaten by a cormorant. Cephalopod beaks were too eroded for measurement and subsequent accurate size estimation, but they generally were of the size class that would be consumed by a seabird and cephalopods have been reported previously in Brandt's Cormorant diet (Hubbs et al. 1970, Baltz and Morejohn 1977, Ainley et al. 1981); therefore, squid and octopus were considered primary prey. Other invertebrates occurred with the following frequency: crabs $(3.9 \%)$, mollusks $(2.8 \%)$, polychaetes $(5.6 \%)$, and shrimps (31.2\%). These invertebrates were unlikely consumed directly by the cormorant because Brandt's Cormorants are visual predators that feed on fishes in motion (Hubbs et al. 1970), they do not have bill morphology conducive to eating invertebrates (Cutler 
1983), and stable isotope analysis performed on diet samples from Southeast Farallon Island in central California did not indicate invertebrate consumption (Sydeman et al. 1997). Samples containing these prey items also contained fishes that eat these invertebrates (Barry et al. 1996). Therefore, crabs, mollusks, polychaetes, and shrimps were considered secondary prey and excluded from the analyses. Isopods were small and likely present from eating fish infected with these parasites.

Overall, neither the nested $250 \mu \mathrm{m}$ sieve nor the all-structure technique increased prey detection. These additional steps in sample processing greatly reduced efficiency and yielded little benefit. The $250 \mu \mathrm{m}$ sieve contained prey remains $56.0 \%$ of the time, but they were almost exclusively secondary prey remains with the remainder being indecipherable parts from fishes. Fish otoliths and cephalopod beaks yielded the greatest counts and taxonomic resolution. Fish bones were too eroded to go beyond family or genus taxonomic level. Other fish parts such as eye lenses, sculpin preopercles, perch teeth, and perch pharyngeal plates occurred frequently, but generally did not contribute more to the fish count than fish otoliths. Cephalopod lenses also did not contribute more to the cephalopod count.

\subsection{Sampling results}

Fifteen pellets were processed from each of 19 sampling days for a total of 285 samples. Of these, $229(80.4 \%)$ had identifiable and enumerable primary prey remains. The remaining 56 samples (19.6\%) either only contained prey likely to have been consumed secondarily (49 samples, or $17.1 \%$ ) or were empty ( 7 samples, $2.5 \%$ ). Of the 
229 samples containing primary prey, 208 (90.8\%) contained only fish remains, 20 (8.7\%) contained fish and cephalopod remains, and $1(0.4 \%)$ contained only cephalopod remains. Occurrence of non-prey items included sediment (27.7\%), plant material (17.9\%), parasitic worms (53.3\%), ticks (1.8\%), and rocks of less than $1 \mathrm{~cm}$ diameter (3.2\%). No man-made materials (e.g. plastics) were found.

\subsection{Diet description}

Brandt's Cormorants fed almost exclusively on fishes $(98 \% \mathrm{~N}, 18$ families and 27 species represented) compared with few invertebrates $(2 \% \mathrm{~N}, 2$ families and 2 species represented; Table 2). Fish taxonomic nomenclature follows Page et al. (2013). Only five fish species each comprised greater than $2.0 \%$ of the diet by mean percent number (Table 3). In both nonbreeding seasons, Northern Anchovy dominated the diet by mean prey-specific number and frequency, although more so during 2006-07 (2006-07: 80.1\%PN and 89.6\%FO, 2007-08: 73.9\%PN and 60.5\%FO). Speckled Sanddab was the second most important prey in the diet with substantial numbers consumed much of the time (2006-07: 34.2\%PN and 29.9\%FO, 2007-08: 45.4\%PN and 44.4\%FO). Moderate numbers of Pacific Sanddab also were consumed with some frequency (2006-07: 16.1\% PN and 17.9\%FO, 2007-08: 19.9\%PN and 24.7\%FO). Topsmelt (Atherinopsis affinis) and Pacific Sardine (Sardinops sagax) were consumed less frequently, but when consumed, were consumed in great number (Topsmelt, 2006-07: 25.0\%PN and 1.5\%FO, 2007-08: 58.4\%PN and 15.4\%FO and Pacific Sardine, 2006-07: 53.7\%PN and 3.0\%FO, 2007-08: 42.7\%PN and 11.1\%FO). 
Table 2. Taxonomic classification, common name, and code for prey species in Brandt's Cormorant diet.

\begin{tabular}{|c|c|c|c|c|}
\hline Order & Family & Species & Common name & Code \\
\hline \multicolumn{5}{|l|}{ Fishes } \\
\hline Atheriniformes & Atherinidae & Atherinopsis affinis & Topsmelt & Aaf \\
\hline Batrachoidiformes & Batrachoididae & Porichthys notatus & Plainfin Midshipman & Pno \\
\hline \multirow[t]{2}{*}{ Clupeiformes } & Clupeidae & Sardinops sagax & Pacific Sardine & Ssa \\
\hline & Engraulididae & Engraulis mordax & Northern Anchovy & Emo \\
\hline Gadiformes & Merluccidae & Merluccius productus & Pacific Hake & $\mathrm{Mpr}$ \\
\hline Ophidiiformes & Ophidiidae & Chilara taylori & Spotted Cusk-eel & Cta \\
\hline \multirow[t]{9}{*}{ Perciformes } & Ammodytidae & Ammodytes hexapterus & Pacific Sandlance & Ahe \\
\hline & Carangidae & Trachurus symmetricus & Jack Mackerel & Tsy \\
\hline & Embiotocidac & Embiotoca lateralis & Striped Seaperch & Ela \\
\hline & & Hypsurus caryi & Rainbow Seaperch & Hca \\
\hline & & Rhacochilus vacca & Pile Surfperch & Rva \\
\hline & & Unidentified perches & Perches & Per \\
\hline & Gobiidae & Rhinogobiops nicholsii & Blackeye Goby & Rni \\
\hline & Sciaenidae & Genyonemus lineatus & White Croaker & Gli \\
\hline & Scombridae & Scomber japonicus & Pacific Mackerel & Sjo \\
\hline \multirow[t]{7}{*}{ Pleuronectiformes } & Bothidae & Citharichthys sordidus & Pacific Sanddab & Cso \\
\hline & & Citharichthys stigmaeus & Speckled Sanddab & Cst \\
\hline & Cynoglossidae & Symphurus atricauda & California Tonguefish & Sat \\
\hline & Pleuronectidae & Eopsetta jordani & Petrale Sole & Ejo \\
\hline & & Lepidopsetta bilineata & Rock Sole & Lbi \\
\hline & & Microstomus pacificus & Dover Sole & Mpa \\
\hline & & Parophrys vetulus & English Sole & Pve \\
\hline \multirow[t]{8}{*}{ Scorpaeniformes } & Cottidae & Artedius lateralis & Smoothhead Sculpin & Ala \\
\hline & & Chitonotus pugetensis & Roughback Sculpin & $\mathrm{Cpu}$ \\
\hline & & Leptocottus armatus & Pacific Staghorn Sculpin & Lar \\
\hline & & Scorpaenichthys marmoratus & Cabezon & Sma \\
\hline & & Unidentified sculpins & Sculpins & $\mathrm{Scu}$ \\
\hline & Hexagrammidae & Ophiodon elongatus & Lingcod & Oel \\
\hline & Scorpaenidae & Sebastes melanops & Black Rockfish & Sme \\
\hline & & Sebastes spp. & Rockfishes & Seb \\
\hline Unid. Teleostei & Unidentified & Unidentified fishes & Unidentified fishes & Uni \\
\hline \multicolumn{5}{|l|}{ Cephalopods } \\
\hline Octopoda & Octopodidae & Octopus rubescens & East Pacific Red Octopus & Oru \\
\hline Teuthida & Loliginidae & Doryteuthis opalescens & Market Squid & Dop \\
\hline
\end{tabular}


Table 3. Brandt's Cormorant diet composition by mean percent number $(\% \mathrm{~N})$, mean percent prey-specific number $(\% \mathrm{PN})$, and frequency of occurrence (\%FO) for combined sampling locations during the 2006-07 nonbreeding season $(n=67), 2007-08$ nonbreeding season $(n=162)$, and 2006-07 and 2007-08 nonbreeding seasons combined $(\mathrm{n}=229)$.

\begin{tabular}{|c|c|c|c|c|c|c|c|c|c|}
\hline \multirow[b]{2}{*}{ Species } & \multicolumn{3}{|c|}{$2006-07$} & \multicolumn{3}{|c|}{$2007-08$} & \multicolumn{3}{|c|}{ 2006-07 and 2007-08 } \\
\hline & $\% \mathrm{~N}$ & $\% \mathrm{PN}$ & $\% \mathrm{FO}$ & $\% \mathrm{~N}$ & $\% \mathrm{PN}$ & $\% \mathrm{FO}$ & $\% \mathrm{~N}$ & $\% \mathrm{PN}$ & $\% \mathrm{FO}$ \\
\hline Engraulis mordax & 71.7 & 80.1 & 89.6 & 44.7 & 73.9 & 60.5 & 52.6 & 76.3 & 69.0 \\
\hline Citharichthys stigmaeus & 10.2 & 34.2 & 29.9 & 20.2 & 45.4 & 44.4 & 17.3 & 43.0 & 40.2 \\
\hline Atherinopsis affinis & 0.4 & 25.0 & 1.5 & 9.0 & 58.4 & 15.4 & 6.5 & 57.1 & 11.4 \\
\hline Citharichthys sordidus & 2.9 & 16.1 & 17.9 & 4.9 & 19.9 & 24.7 & 4.3 & 19.1 & 22.7 \\
\hline Sardinops sagax & 1.6 & 53.7 & 3.0 & 4.7 & 42.7 & 11.1 & 3.8 & 43.8 & 8.7 \\
\hline Unidentified perches & 1.9 & 25.8 & 7.5 & 2.0 & 20.1 & 9.9 & 2.0 & 21.5 & 9.2 \\
\hline Unidentified sculpins & 2.4 & 23.2 & 10.4 & 1.3 & 10.4 & 12.3 & 1.6 & 13.7 & 11.8 \\
\hline Unidentified fishes & 2.5 & 10.0 & 25.4 & 0.8 & 11.4 & 7.4 & 1.3 & 10.6 & 12.7 \\
\hline Octopus rubescens & 0.1 & 7.1 & 1.5 & 1.7 & 19.2 & 8.6 & 1.2 & 18.4 & 6.6 \\
\hline Parophrys vetulus & 0.0 & 0.0 & 0.0 & 1.6 & 12.9 & 12.3 & 1.1 & 12.9 & 8.7 \\
\hline Sebastes spp. & 0.2 & 13.3 & 1.5 & 1.5 & 48.4 & 3.1 & 1.1 & 42.6 & 2.6 \\
\hline Porichthys notatus & 1.1 & 18.0 & 6.0 & 1.0 & 12.7 & 8.0 & 1.0 & 13.9 & 7.4 \\
\hline Leptocottus armatus & 1.0 & 10.8 & 9.0 & 0.9 & 7.0 & 13.0 & 0.9 & 7.8 & 11.8 \\
\hline Doryteuthis opalescens & 1.5 & 100.0 & 1.5 & 0.5 & 21.0 & 2.5 & 0.8 & 36.8 & 2.2 \\
\hline Ammodytes hexapterus & $<0.1$ & 2.1 & 1.5 & 0.7 & 18.8 & 3.7 & 0.5 & 16.4 & 3.1 \\
\hline Microstomus pacificus & 0.0 & 0.0 & 0.0 & 0.7 & 18.7 & 3.7 & 0.5 & 18.7 & 2.6 \\
\hline Rhacochilus vacca & 0.5 & 33.3 & 1.5 & 0.3 & 26.7 & 1.2 & 0.4 & 28.9 & 1.3 \\
\hline Embiotoca lateralis & 0.2 & 6.3 & 3.0 & 0.4 & 14.4 & 3.1 & 0.4 & 12.1 & 3.1 \\
\hline Trachurus symmetricus & 0.0 & 0.0 & 0.0 & 0.5 & 41.7 & 1.2 & 0.4 & 41.7 & 0.9 \\
\hline Sebastes melanops & 1.1 & 72.7 & 1.5 & 0.1 & 10.0 & 0.6 & 0.4 & 41.4 & 0.9 \\
\hline Scorpaenichthys marmoratus & 0.0 & 0.0 & 0.0 & 0.5 & 41.1 & 1.2 & 0.4 & 41.1 & 0.9 \\
\hline Merluccius productus & 0.0 & 0.0 & 0.0 & 0.5 & 75.0 & 0.6 & 0.3 & 75.0 & 0.4 \\
\hline Genyonemus lineatus & 0.2 & 6.1 & 3.0 & 0.2 & 13.1 & 1.9 & 0.2 & 10.3 & 2.2 \\
\hline Chilara taylori & 0.2 & 5.2 & 3.0 & 0.2 & 12.6 & 1.9 & 0.2 & 9.6 & 2.2 \\
\hline Scomber japonicus & 0.1 & 7.1 & 1.5 & 0.2 & 9.6 & 2.5 & 0.2 & 9.1 & 2.2 \\
\hline Rhinogobiops nicholsii & 0.0 & 0.0 & 0.0 & 0.2 & 33.3 & 0.6 & 0.1 & 33.3 & 0.4 \\
\hline Symphurus atricauda & 0.1 & 4.6 & 3.0 & 0.1 & 5.8 & 2.5 & 0.1 & 5.4 & 2.6 \\
\hline Artedius lateralis & 0.0 & 0.0 & 0.0 & 0.1 & 20.0 & 0.6 & 0.1 & 20.0 & 0.4 \\
\hline Ophiodon elongatus & $<0.1$ & 0.4 & 1.5 & 0.1 & 14.7 & 0.6 & 0.1 & 7.5 & 0.9 \\
\hline Chitonotus pugetensis & 0.0 & 0.0 & 0.0 & 0.1 & 3.5 & 2.5 & 0.1 & 3.5 & 1.7 \\
\hline Hypsurus caryi & 0.1 & 6.3 & 1.5 & 0.0 & 0.0 & 0.0 & $<0.1$ & 6.3 & 0.4 \\
\hline Eopsetta jordani & 0.0 & 0.0 & 0.0 & $<0.1$ & 2.0 & 1.2 & $<0.1$ & 2.0 & 0.9 \\
\hline Lepidopsetta bilineata & 0.0 & 0.0 & 0.0 & $<0.1$ & 2.6 & 0.6 & $<0.1$ & 2.6 & 0.4 \\
\hline
\end{tabular}

Precision (SE) of \% PN was calculated using resampled means for the top five species consumed (Fig. 4). Variation stabilized for all 5 species indicating sufficient samples had been examined. The sample size required ranged from 12 to 50 samples. Fewer samples were required for prey consumed in smaller numbers and less frequently (Pacific Sanddab, Topsmelt, and Pacific Sardine) than for prey consumed in larger numbers more frequently (Northern Anchovy and Speckled Sanddab). 

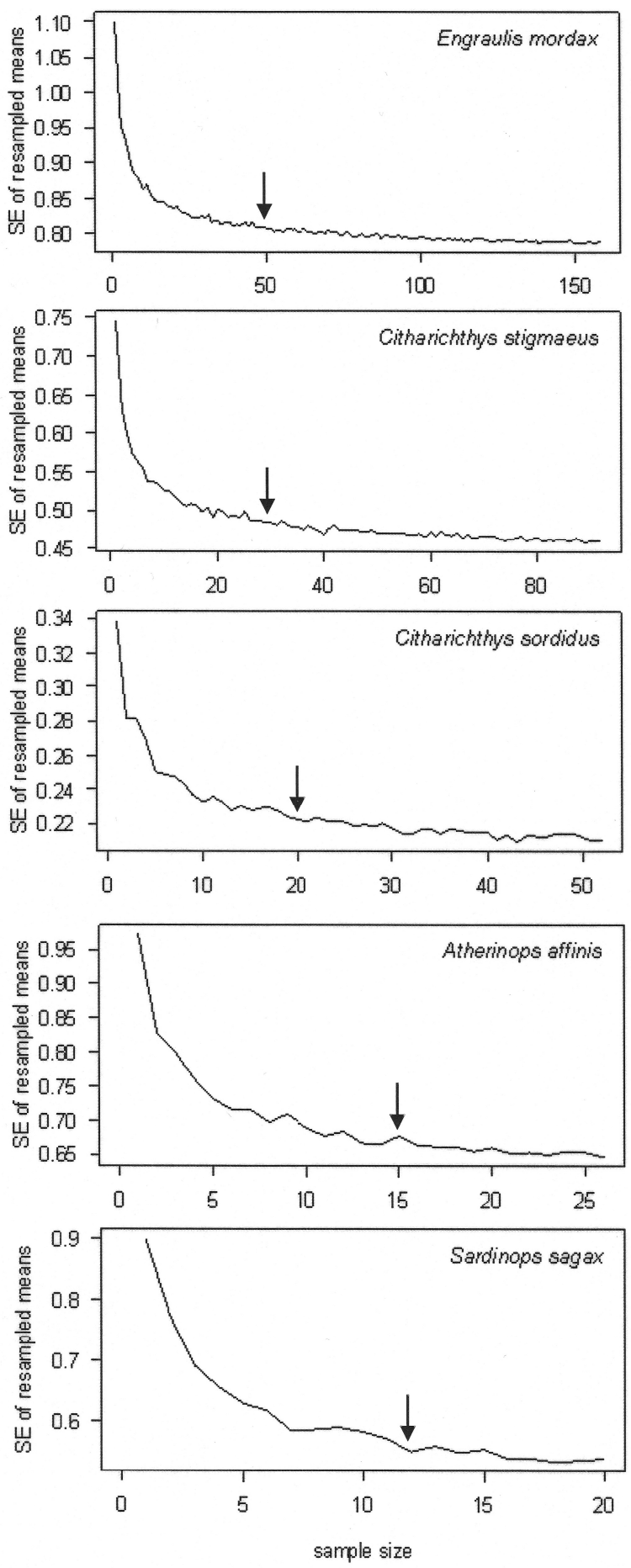

Figure 4. Precision (SE) of resampled means for percent prey-specific number $(\% \mathrm{PN})$ for the top five prey species. Sufficient sample size was obtained where precision stabilized and is denoted by an arrow. 
Cumulative prey curves generated from samples reached an asymptote at $\mathrm{n}=84$ samples for the 2006-07 nonbreeding season and $n=100$ samples for the 2007-08 nonbreeding season indicating adequate sample size had been obtained to characterize the overall number of prey categories consumed in those years (Fig. 5). The estimated number of prey categories was 22 for the 2006-07 nonbreeding season and 29 for the 2007-08 nonbreeding season.
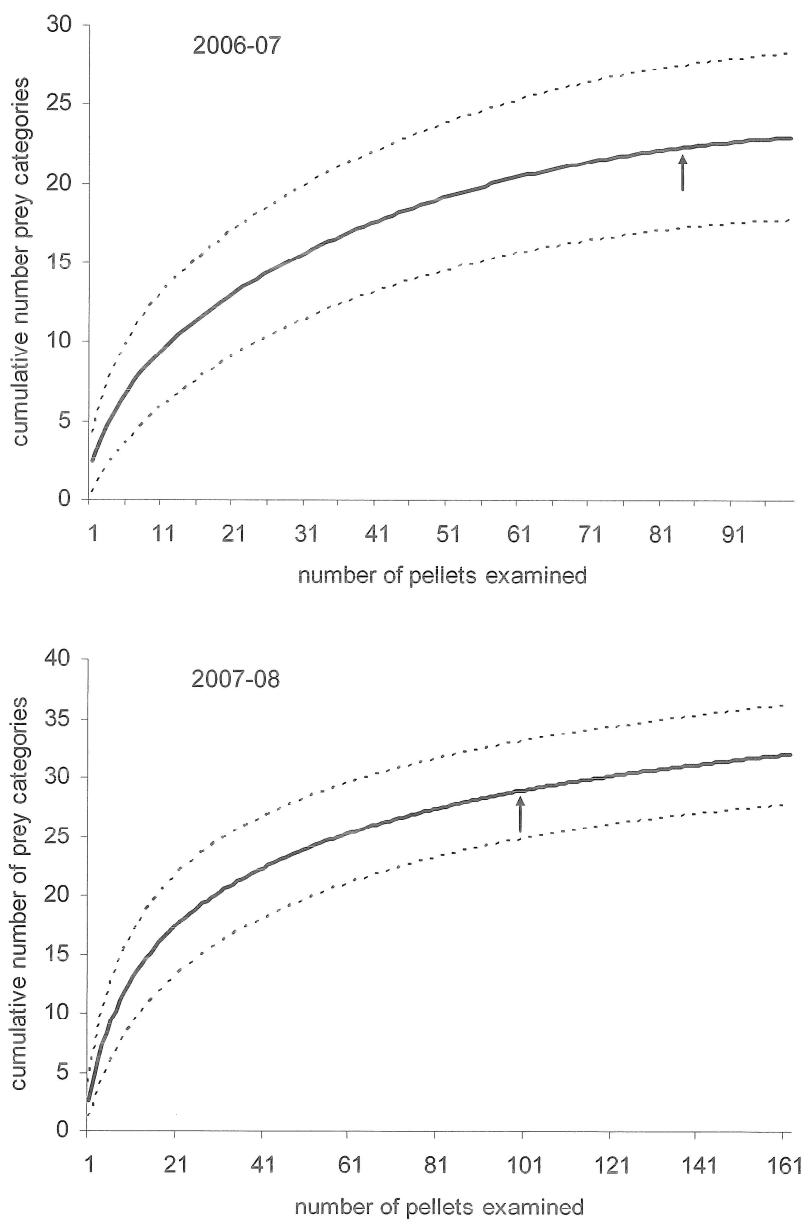

Figure 5. Cumulative number of prey categories (solid line) and 95\% confidence intervals (dashed lines) for the diet of Brandt's Cormorant during the 2006-07 and 2007-08 nonbreeding seasons. Sufficient sample size was obtained where the slope is statistically equivalent to zero and is denoted by an arrow at $\mathrm{n}=84$ ( 22 prey categories) for 2006-07 and $n=100$ (29 prey categories) for 2007-08. 
Northern Anchovy dominated the diet, especially at the outer coast (Año Nuevo

Island 69.8\% N, Moss Landing Harbor 45.0\%N, and Monterey Harbor 39.7\%N; Table 4).

Other important prey $(>5 \% \mathrm{~N})$ were Pacific Sardine $(6.5 \% \mathrm{~N})$ at Año Nuevo Island,

Speckled Sanddab (28.6\%N), Pacific Sanddab (7.3\%N), and Topsmelt $(5.9 \% \mathrm{~N})$ at Moss

Landing Harbor, and Speckled Sanddab (19.1\%N) and Topsmelt (15.8\%) at Monterey

Harbor.

Table 4. Brandt's Cormorant diet composition by mean percent number $(\% \mathrm{~N})$, mean percent prey-specific number $(\% \mathrm{PN})$, and frequency of occurrence $(\% \mathrm{FO})$ at Año Nuevo Island $(\mathrm{n}=82)$, Moss Landing Harbor $(\mathrm{n}=92)$, and Monterey Harbor $(\mathrm{n}=55)$.

\begin{tabular}{|c|c|c|c|c|c|c|c|c|c|}
\hline \multirow[b]{2}{*}{ Species } & \multicolumn{3}{|c|}{$\begin{array}{c}\text { Año Nuevo Island } \\
\text { 2006-07 and 2007-08 }\end{array}$} & \multicolumn{3}{|c|}{$\begin{array}{l}\text { Moss Landing Harbor } \\
2006-07 \text { and 2007-08 }\end{array}$} & \multicolumn{3}{|c|}{$\begin{array}{c}\text { Monterey Harbor } \\
\text { 2007-08 }\end{array}$} \\
\hline & $\% \mathrm{~N}$ & $\% \mathrm{PN}$ & $\% \mathrm{FO}$ & $\% \mathrm{~N}$ & $\% \mathrm{PN}$ & $\% \mathrm{FO}$ & $\% \mathrm{~N}$ & $\% \mathrm{PN}$ & $\% \mathrm{FO}$ \\
\hline Engraulis mordax & 69.8 & 88.1 & 79.3 & 45.0 & 64.7 & 69.6 & 39.7 & 75.3 & 52.7 \\
\hline Sardinops sagax & 6.5 & 58.9 & 11.0 & 1.2 & 28.3 & 4.3 & 4.2 & 33.3 & 12.7 \\
\hline Unidentified perches & 4.3 & 39.5 & 11.0 & 1.0 & 9.3 & 10.9 & $<0.1$ & 1.2 & 3.6 \\
\hline Citharichthys stigmaeus & 3.3 & 33.7 & 9.8 & 28.6 & 46.2 & 62.0 & 19.1 & 39.0 & 49.1 \\
\hline Unidentified sculpins & 2.3 & 48.0 & 4.9 & 0.9 & 5.6 & 16.3 & 1.7 & 12.0 & 14.5 \\
\hline Octopus rubescens & 1.7 & 46.4 & 3.7 & 0.3 & 5.5 & 5.4 & 2.0 & 15.6 & 12.7 \\
\hline Sebastes spp. & 1.7 & 46.1 & 3.7 & 0.3 & 25.0 & 1.1 & 1.7 & 46.0 & 3.6 \\
\hline Unidentified fishes & 1.5 & 14.1 & 11.0 & 1.2 & 8.2 & 15.2 & 1.2 & 10.8 & 10.9 \\
\hline Parophrys vetulus & 1.2 & 47.7 & 2.4 & 1.5 & 10.1 & 15.2 & 0.4 & 5.3 & 7.3 \\
\hline Citharichthys sordidus & 1.0 & 16.8 & 6.1 & 7.3 & 19.2 & 38.0 & 4.3 & 19.6 & 21.8 \\
\hline Leptocottus armatus & 1.0 & 16.8 & 6.1 & 0.8 & 4.4 & 18.5 & 1.0 & 10.5 & 9.1 \\
\hline Porichthys notatus & 1.0 & 20.4 & 4.9 & 1.2 & 10.8 & 10.9 & 0.9 & 15.7 & 5.5 \\
\hline Scorpaenichthys marmoratus & 1.0 & 80.0 & 1.2 & $<0.1$ & 2.2 & 1.1 & 0.0 & 0.0 & 0.0 \\
\hline Atherinopsis affinis & 0.9 & 37.5 & 2.4 & 5.9 & 49.3 & 12.0 & 15.8 & 66.7 & 23.6 \\
\hline Sebastes melanops & 0.9 & 72.7 & 1.2 & 0.0 & 0.0 & 0.0 & 0.2 & 10.0 & 1.8 \\
\hline Rhacochilus vacca & 0.7 & 26.7 & 2.4 & 0.0 & 0.0 & 0.0 & 0.6 & 33.3 & 1.8 \\
\hline Rhinogobiops nicholsii & 0.4 & 33.3 & 1.2 & 0.0 & 0.0 & 0.0 & 0.0 & 0.0 & 0.0 \\
\hline Artedius lateralis & 0.2 & 20.0 & 1.2 & 0.0 & 0.0 & 0.0 & 0.0 & 0.0 & 0.0 \\
\hline Embiotoca lateralis & 0.2 & 6.6 & 3.7 & 0.1 & 6.8 & 2.2 & 0.9 & 25.6 & 3.6 \\
\hline Genyonemus lineatus & 0.1 & 6.1 & 2.4 & 0.4 & 13.1 & 3.3 & 0.0 & 0.0 & 0.0 \\
\hline Hypsurus caryi & 0.1 & 6.3 & 1.2 & 0.0 & 0.0 & 0.0 & 0.0 & 0.0 & 0.0 \\
\hline Chilara taylori & $<0.1$ & 3.7 & 1.2 & 0.4 & 13.4 & 3.3 & 0.1 & 4.2 & 1.8 \\
\hline Lepidopsetta bilineata & $<0.1$ & 2.6 & 1.2 & 0.0 & 0.0 & 0.0 & 0.0 & 0.0 & 0.0 \\
\hline Microstomus pacificus & 0.0 & 0.0 & 0.0 & 0.1 & 2.5 & 3.3 & 1.9 & 34.9 & 5.5 \\
\hline Trachurus symmetricus & 0.0 & 0.0 & 0.0 & 0.0 & 0.0 & 0.0 & 1.5 & 41.7 & 3.6 \\
\hline Doryteuthis opalescens & 0.0 & 0.0 & 0.0 & 1.2 & 27.3 & 4.3 & 1.4 & 75.0 & 1.8 \\
\hline Scomber japonicus & 0.0 & 0.0 & 0.0 & 0.1 & 3.7 & 3.3 & 0.6 & 17.3 & 3.6 \\
\hline Symphurus atricauda & 0.0 & 0.0 & 0.0 & 0.1 & 3.3 & 3.3 & 0.4 & 7.5 & 5.5 \\
\hline Ammodytes hexapterus & 0.0 & 0.0 & 0.0 & 1.1 & 19.8 & 5.4 & 0.3 & 7.9 & 3.6 \\
\hline Chitonotus pugetensis & 0.0 & 0.0 & 0.0 & 0.1 & 3.7 & 2.2 & 0.1 & 3.4 & 3.6 \\
\hline Eopsetta jordani & 0.0 & 0.0 & 0.0 & $<0.1$ & 2.9 & 1.1 & $<0.1$ & 1.1 & 1.8 \\
\hline Merluccius productus & 0.0 & 0.0 & 0.0 & 0.8 & 75.0 & 1.1 & 0.0 & 0.0 & 0.0 \\
\hline Ophiodon elongatus & 0.0 & 0.0 & 0.0 & 0.2 & 7.5 & 2.2 & 0.0 & 0.0 & 0.0 \\
\hline
\end{tabular}


Spatiotemporal differences in diet by location and nonbreeding season were compared using feeding strategy diagrams (Fig. 6). Diet composition was similar at Año Nuevo Island during both nonbreeding seasons. Northern Anchovy was the dominant prey, occurring frequently (2006-07: 87.9\%FO; 2007-08: 73.5\%FO), and when consumed, it was consumed in great number (2006-07: 84.8\%PN; 2007-08: 90.7\%PN; Table 5 and Table 6$)$. Ancillary prey $(<50 \%$ FO and $\geq 50 \% \mathrm{PN})$, included a similar mix of benthic and pelagic fishes with Black Rockfish, sculpins, and Pacific Sardine during 2006-07 compared with Cabezon (Scorpaenichthys marmoratus), rockfishes, Pacific Sardine, and Topsmelt during 2007-08. 

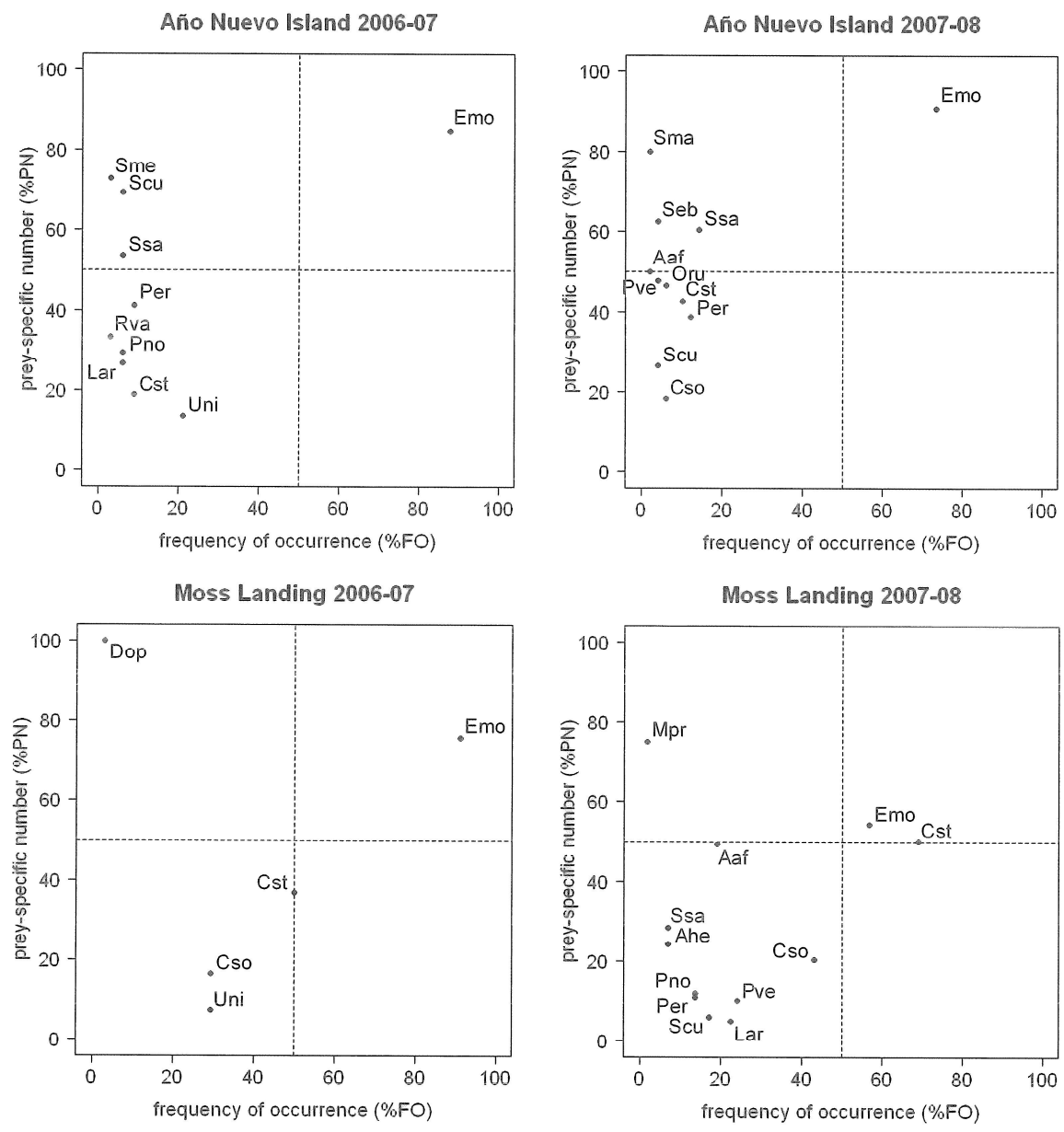

$\begin{array}{ll}\text { Species codes: } \\ \text { Aaf } & \text { Topsmelt } \\ \text { Ahe } & \text { Pacific Sandlance } \\ \text { Cso } & \text { Pacific Sanddab } \\ \text { Cst } & \text { Speckled Sanddab } \\ \text { Dop } & \text { Market Squid } \\ \text { Emo } & \text { Northern Anchovy } \\ \text { Lar } & \text { Pacific Staghorn Sculpin } \\ \text { Mpa } & \text { Dover Sole } \\ \text { Mpr } & \text { Pacific Hake } \\ \text { Oru } & \text { Octopus } \\ \text { Per } & \text { Perches } \\ \text { Pno } & \text { Plainfin Midshipman } \\ \text { Pve } & \text { English Sole } \\ \text { Rva } & \text { Pile Surfperch } \\ \text { Scu } & \text { Sculpins } \\ \text { Seb } & \text { Rockfishes } \\ \text { Sma } & \text { Cabezon } \\ \text { Sme } & \text { Black Rockfish } \\ \text { Ssa } & \text { Pacific Sardine } \\ \text { Tsy } & \text { Jack Mackerel } \\ \text { Uni } & \text { Unidentifiable fishes }\end{array}$

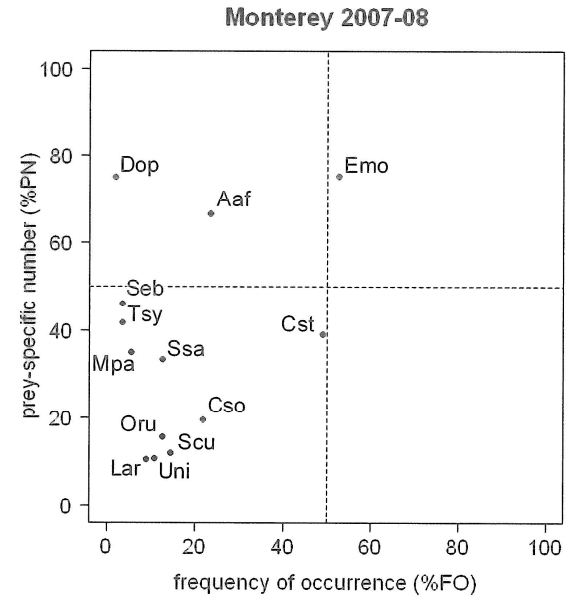

Figure 6. Feeding strategy diagrams for Brandt's Cormorant diet by location and nonbreeding season. 
Table 5. Brandt's Cormorant diet composition by mean percent number $(\% \mathrm{~N})$, cumulative mean percent number (Cumulative $\% \mathrm{~N})$, mean percent prey-specific number $(\% \mathrm{PN})$, and frequency of occurrence (\%FO) during 2006-07 nonbreeding season at Año Nuevo Island $(\mathrm{n}=33)$ and Moss Landing Harbor $(\mathrm{n}=34)$.

\begin{tabular}{lrrrr}
\hline \hline & \multicolumn{4}{c}{ Año Nuevo Island 2006-07 } \\
Species & \%N & Cumulative \%N & $\% \mathrm{PN}$ & $\% \mathrm{FO}$ \\
\hline Engraulis mordax & 74.5 & 74.5 & 84.8 & 87.9 \\
Unidentified sculpins & 4.2 & 78.7 & 69.4 & 6.1 \\
Unidentified perches & 3.7 & 82.4 & 41.2 & 9.1 \\
Sardinops sagax & 3.3 & 85.7 & 53.7 & 6.1 \\
Unidentified fishes & 2.9 & 88.6 & 13.5 & 21.2 \\
Sebastes melanops & 2.2 & 90.8 & 72.7 & 3.0 \\
Porichthys notatus & 1.8 & 92.6 & 29.5 & 6.1 \\
Citharichthys stigmaeus & 1.7 & 94.3 & 18.9 & 9.1 \\
Leptocottus armatus & 1.6 & 95.9 & 26.7 & 6.1 \\
Rhacochilus vacca & 1.0 & 96.9 & 33.3 & 3.0 \\
& \multicolumn{4}{c}{} \\
\hline \multicolumn{4}{c}{ Moss Landing Harbor $2006-07$} \\
Species & $\% \mathrm{~N}$ & Cumulative \%N & $\% \mathrm{PN}$ & $\% \mathrm{FO}$ \\
\hline Engraulis mordax & 69.0 & 69.0 & 75.7 & 91.2 \\
Citharichthys stigmaeus & 18.5 & 87.5 & 36.9 & 50.0 \\
Citharichthys sordidus & 4.8 & 92.3 & 16.5 & 29.4 \\
Doryteuthis opalescens & 2.9 & 95.3 & 100.0 & 2.9 \\
Unidentified fishes & 2.2 & 97.5 & 7.5 & 29.4 \\
\hline
\end{tabular}


Table 6. Brandt's Cormorant diet composition by mean percent number $(\% \mathrm{~N})$, cumulative mean percent number (Cumulative $\% \mathrm{~N})$, mean percent prey-specific number $(\% \mathrm{PN})$, and frequency of occurrence $(\% \mathrm{FO})$ during 2007-08 nonbreeding season at Año Nuevo Island $(n=49)$, Moss Landing Harbor $(n=58)$, and Monterey Harbor $(n=55)$.

\begin{tabular}{|c|c|c|c|c|}
\hline \multirow[b]{2}{*}{ Species } & \multicolumn{4}{|c|}{ Año Nuevo Island 2007-08 } \\
\hline & $\% \mathrm{~N}$ & Cumulative $\% \mathrm{~N}$ & $\% \mathrm{PN}$ & $\% \mathrm{FO}$ \\
\hline Engraulis mordax & 66.7 & 66.7 & 90.7 & 73.5 \\
\hline Sardinops sagax & 8.6 & 75.3 & 60.4 & 14.3 \\
\hline Unidentified perches & 4.7 & 80.0 & 38.6 & 12.2 \\
\hline Citharichthys stigmaeus & 4.3 & 84.4 & 42.6 & 10.2 \\
\hline Octopus rubescens & 2.8 & 87.2 & 46.4 & 6.1 \\
\hline Sebastes spp. & 2.6 & 89.7 & 62.5 & 4.1 \\
\hline Parophrys vetulus & 1.9 & 91.7 & 47.7 & 4.1 \\
\hline Scorpaenichthys marmoratus & 1.6 & 93.3 & 80.0 & 2.0 \\
\hline Citharichthys sordidus & 1.1 & 94.5 & 18.4 & 6.1 \\
\hline Unidentified sculpins & 1.1 & 95.5 & 26.5 & 4.1 \\
\hline \multirow{2}{*}{ Atherinopsis affinis } & 1.0 & 96.6 & 50.0 & 2.0 \\
\hline & \multicolumn{4}{|c|}{ Moss Landing Harbor 2007-08 } \\
\hline Species & $\% \mathrm{~N}$ & Cumulative $\% \mathrm{~N}$ & $\% \mathrm{PN}$ & $\% \mathrm{FO}$ \\
\hline Citharichthys stigmaeus & 34.6 & 34.6 & 50.1 & 69.0 \\
\hline Engraulis mordax & 30.9 & 65.5 & 54.3 & 56.9 \\
\hline Atherinopsis affinis & 9.4 & 74.8 & 49.3 & 19.0 \\
\hline Citharichthys sordidus & 8.7 & 83.6 & 20.3 & 43.1 \\
\hline Parophrys vetulus & 2.4 & 86.0 & 10.1 & 24.1 \\
\hline Sardinops sagax & 1.9 & 88.0 & 28.3 & 6.9 \\
\hline Ammodytes hexapterus & 1.7 & 89.6 & 24.2 & 6.9 \\
\hline Porichthys notatus & 1.6 & 91.3 & 11.9 & 13.8 \\
\hline Unidentified perches & 1.5 & 92.8 & 11.0 & 13.8 \\
\hline Merluccius productus & 1.3 & 94.1 & 75.0 & 1.7 \\
\hline Leptocottus armatus & 1.1 & 95.2 & 4.9 & 22.4 \\
\hline \multirow[t]{2}{*}{ Unidentified sculpins } & 1.0 & 96.2 & 6.0 & 17.2 \\
\hline & \multicolumn{4}{|c|}{ Monterey Harbor 2007-08 } \\
\hline Species & $\% \mathrm{~N}$ & Cumulative $\% \mathrm{~N}$ & $\% \mathrm{PN}$ & $\% \mathrm{FO}$ \\
\hline Engraulis mordax & 39.7 & 39.7 & 75.3 & 52.7 \\
\hline Citharichthys stigmaeus & 19.1 & 58.8 & 39.0 & 49.1 \\
\hline Atherinopsis affinis & 15.8 & 74.6 & 66.7 & 23.6 \\
\hline Citharichthys sordidus & 4.3 & 78.9 & 19.6 & 21.8 \\
\hline Sardinops sagax & 4.2 & 83.1 & 33.3 & 12.7 \\
\hline Octopus rubescens & 2.0 & 85.1 & 15.6 & 12.7 \\
\hline Microstomus pacificus & 1.9 & 87.0 & 34.9 & 5.5 \\
\hline Unidentified sculpins & 1.7 & 88.8 & 12.0 & 14.5 \\
\hline Sebastes spp. & 1.7 & 90.4 & 46.0 & 3.6 \\
\hline Trachurus symmetricus & 1.5 & 92.0 & 41.7 & 3.6 \\
\hline Doryteuthis opalescens & 1.4 & 93.3 & 75.0 & 1.8 \\
\hline Unidentified fishes & 1.2 & 94.5 & 10.8 & 10.9 \\
\hline Leptocottus armatus & 1.0 & 95.5 & 10.5 & 9.1 \\
\hline
\end{tabular}


In contrast, at Moss Landing Harbor the feeding strategy differed between nonbreeding seasons (Fig. 6). Northern Anchovy dominated during 2006-07 (75.7\%PN, 91.2\%FO) and although infrequent, Market Squid was consumed (100.0\%PN, 2.9\%FO; Table 5 and Table 6). Speckled Sanddab was moderately consumed (36.9\%PN, $50.0 \%$ FO) and Pacific Sanddab was rarely consumed (16.5\%PN, 29.4\%FO). During 2007-08, Northern Anchovy decreased in number and frequency and Speckled Sanddab increased in number and frequency so that they were equally important (Northern Anchovy: 30.9\%N, Speckled Sanddab: 34.6\%N). Topsmelt, which was not present during 2006-07, was moderately consumed (49.3\%PN, 19.0\%FO). Pacific Hake was consumed infrequently $(75.0 \% \mathrm{PN}, 1.7 \% \mathrm{FO})$.

Monterey Harbor was sampled only during 2007-08. Northern Anchovy was dominant (75.3\%PN, 52.7\%FO; Table 6; Fig. 6). Speckled Sanddab and Topsmelt were consumed in appreciable numbers $(39.0 \% \mathrm{PN}$ and $66.7 \% \mathrm{PN}$, respectively) and frequency (49.1\%FO and $23.6 \%$, respectively). Market Squid was consumed infrequently $(75.0 \% \mathrm{PN}, 1.8 \% \mathrm{FO})$.

Overall, Northern Anchovy was the primary prey at all locations and Speckled Sanddab was important at locations inside Monterey Bay, Moss Landing Harbor and Monterey Harbor. In addition, all locations except Moss Landing Harbor during 2006-07 included a unique and diverse set of benthic and pelagic prey that were consumed in smaller numbers and infrequently $(<50 \% \mathrm{FO}$ and $<50 \% \mathrm{PN})$. 


\subsection{Prey number and diversity}

For analysis of variance tests of prey number and diversity, normality (KS test) and equal variance (Levene's test) assumptions were met unless otherwise stated and all statistical tests were performed at $\alpha=0.05$ (SYSTAT 12.0). Least squares plots and boxplots with median, first and third quartiles, and $95 \%$ confidence intervals were examined to aid interpretation.

When comparing mean prey number during the 2006-07 nonbreeding season among time periods and between locations, there was no significant interaction between the main effects (two-way ANOVA, Model I, $\mathrm{F}_{2,48}=1.011, \mathrm{p}=0.371$; Table 7); therefore, the main effect hypotheses were investigated. Mean prey number ranged from 5.9 during winter to 13.3 during postbreeding, but did not significantly differ among time periods $\left(\mathrm{F}_{2,48}=2.267, \mathrm{p}=0.115\right)$. Mean prey number was not significantly different between locations (9.2 at Año Nuevo Island and 10.6 at Moss Landing Harbor; $F_{1,48}=$ $0.171, \mathrm{p}=0.681)$. Median prey number at Año Nuevo Island and Moss Landing Harbor were similar and prey number was less during winter at both locations (Fig. 7). Prey number was greatest during prebreeding at Año Nuevo Island with a mean of 17.4 prey. 
Table 7. Two-way ANOVA results comparing prey number among time periods and between locations during the 2006-07 nonbreeding season.

\begin{tabular}{lrrrr}
\hline \hline Time period & LS mean & SE & n & ANOVA \\
\hline Postbreeding & 13.3 & 0.3 & 18 & \\
Winter & 5.9 & 0.3 & 18 & $\mathrm{~F}_{1,48}=2.267, \mathrm{p}=0.115$ \\
Prebreeding & 12.0 & 0.3 & 18 & \\
\hline Location & & & & ANOVA \\
\hline ANI & LS mean & SE & $\mathrm{n}$ & ANOVA \\
MLH & 10.6 & 0.2 & 27 & \multirow{2}{*}{$\mathrm{F}_{1,48}=0.171, \mathrm{p}=0.681$} \\
& 9.2 & 0.2 & 27 & \\
\hline Time period*Location & LS mean & SE & $\mathrm{n}$ & \\
\hline Postbreeding ANI & 13.5 & 0.4 & 9 & \\
Winter ANI & 4.8 & 0.4 & 9 & \\
Prebreeding ANI & 17.4 & 0.4 & 9 & $\mathrm{~F}_{2,48}=1.011, \mathrm{p}=0.371$ \\
Postbreeding MLH & 13.0 & 0.4 & 9 & \\
Winter MLH & 7.3 & 0.4 & 9 & \\
Prebreeding MLH & 8.3 & 0.4 & 9 & \\
\hline
\end{tabular}



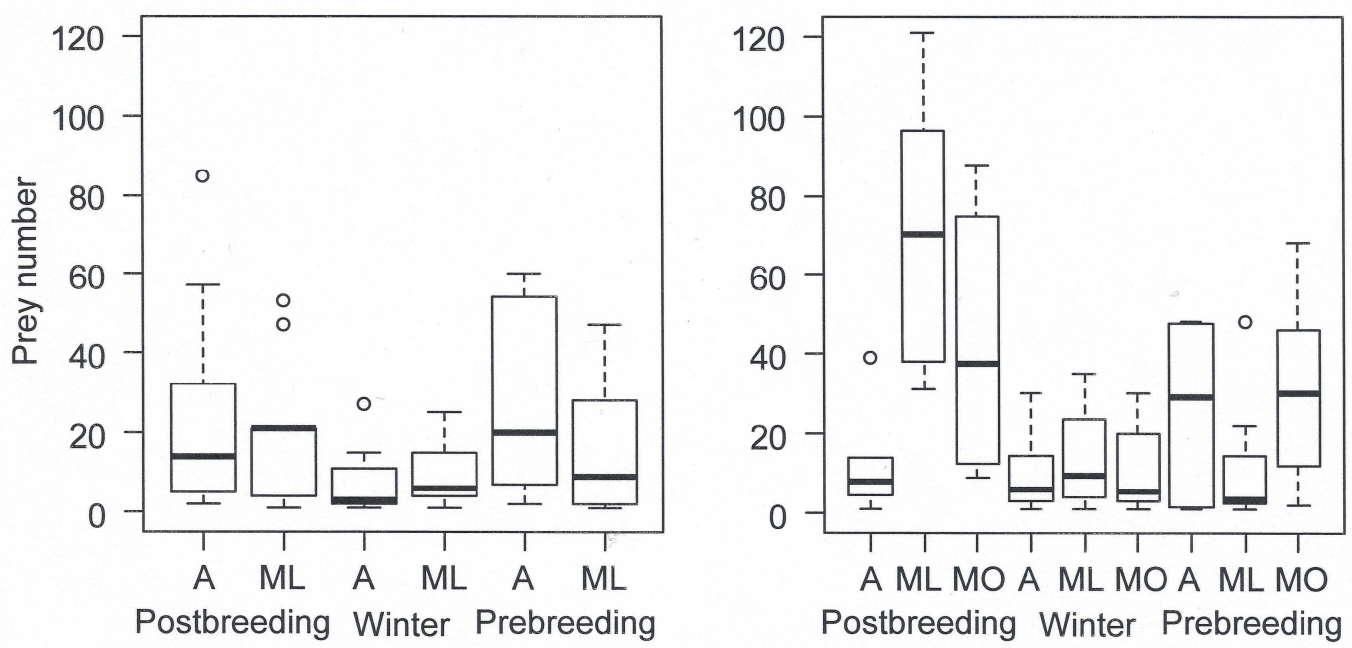

Figure 7. Number of prey consumed in Brandt's Cormorant diet by time period (postbreeding, winter, and prebreeding) and location $(\mathrm{A}=$ Año Nuevo Island, $\mathrm{ML}=$ Moss Landing Harbor, $\mathrm{MO}=$ Monterey Harbor) during the 2006-07 $(\mathrm{n}=9, \mathrm{~N}=54)$ and 2007-08 $(\mathrm{n}=8, \mathrm{~N}=72)$ nonbreeding seasons. Boxplots indicate medians (line), first and third quartiles (bottom and top of box), 95\% confidence intervals (whiskers), and outliers (points).

When comparing mean prey number among time periods and among locations during the 2007-08 nonbreeding season there was a significant interaction (two-way ANOVA, Model I, $\mathrm{F}_{4,63}=4.122, \mathrm{p}=0.005$; Table 8); therefore, main effects could not be interpreted. The pattern over time was different for all three locations. At Año Nuevo Island, mean prey number was least during postbreeding and winter and increased to 12.7 during prebreeding. Moss Landing Harbor had the greatest mean prey number during postbreeding, 62.6 prey per bird per day, the greatest of any time during the study, followed by a decrease to 8.8 during winter, and then a decrease to 5.8 during prebreeding. Monterey Harbor also had greater mean prey number during postbreeding 
at 31.4 prey, was least during winter at 7.0 prey, and then increased to 21.3 prey during prebreeding (Fig. 7). Tukey's HSD test for time periods indicated that overall in the region, birds consumed significantly greater number of prey during postbreeding than winter $(\mathrm{p}=0.001)$ and prebreeding $(\mathrm{p}=0.051)$, but winter and prebreeding were not significantly different $(\mathrm{p}=0.345)$. Mean prey number was variable during the 2007-08 nonbreeding season and overall location differences were not significantly different (Tukey's HSD). The ANOVA least squares means plot for location indicated that birds using Año Nuevo Island ate less prey than at Moss Landing Harbor and Monterey Harbor.

Table 8. Two-way ANOVA and multiple comparison test results comparing prey number among time periods and locations during the 2007-08 nonbreeding season.

\begin{tabular}{lrccr}
\hline \hline Time period & LS mean & SE & $\mathrm{n}$ & Tukey's HSD \\
\hline Postbreeding & 24.9 & 0.2 & 24 & Post, Winter: $\mathrm{p}=0.001$ \\
Winter & 7.4 & 0.2 & 24 & Winter, Pre: $\mathrm{p}=0.345$ \\
Prebreeding & 11.7 & 0.2 & 24 & Pre, Post: $\mathrm{p}=0.051$ \\
\hline Location & LS mean & SE & $\mathrm{n}$ & Tukey's HSD \\
\hline ANI & 8.6 & 0.2 & 24 & ANI, MLH: $\mathrm{p}=0.189$ \\
MLH & 15.2 & 0.2 & 24 & MLH, MOH: $\mathrm{p}=0.931$ \\
MOH & 17.0 & 0.2 & 24 & MOH, ANI: $\mathrm{p}=0.092$ \\
& & & & \\
\hline Time period*Location & LS mean & SE & $\mathrm{n}$ & ANOVA \\
\hline Postbreeding ANI & 7.5 & 0.4 & 8 & \\
Winter ANI & 6.5 & 0.4 & 8 & \\
Prebreeding ANI & 12.7 & 0.4 & 8 & \\
Postbreeding MLH & 62.6 & 0.4 & 8 & \\
Winter MLH & 8.8 & 0.4 & 8 & $\mathrm{~F}_{4,63}=4.122, \mathrm{p}=0.005$ \\
Prebreeding MLH & 5.8 & 0.4 & 8 & \\
Postbreeding MOH & 31.4 & 0.4 & 8 & \\
Winter MOH & 7.0 & 0.4 & 8 & \\
Prebreeding MOH & 21.3 & 0.4 & 8 & \\
\hline
\end{tabular}


When comparing mean prey number during 2006-07 and 2007-08 nonbreeding seasons there was a significant interaction between nonbreeding season, time period, and location (multifactorial ANOVA, Model I, $\mathrm{F}_{2,84}=3.362, \mathrm{p}=0.039$; Table 9); therefore, main effects could not be interpreted. Mean prey number was not significantly different during 2006-07 compared with 2007-08 (Tukey's HSD, $\mathrm{p}=0.671$ ). Within nonbreeding season, the only significant difference was that prey number was greater during postbreeding compared with winter (Tukey's HSD, $\mathrm{p}=0.007$ ). Overall, prey number was not significantly different between Año Nuevo Island and Moss Landing Harbor (Tukey's HSD, $p=0.373$ ), the only two locations sampled during both nonbreeding seasons. The overall pattern for mean prey number was consistent between nonbreeding seasons: greater during postbreeding, especially at Moss Landing Harbor, lesser during winter at both locations, and greater during prebreeding at only Año Nuevo Island (Fig. 7). 
Table 9. Three-way ANOVA and multiple comparison test results comparing prey number between 2006-07 and 2007-08 nonbreeding seasons, among time periods within nonbreeding seasons, and between locations.

\begin{tabular}{|c|c|c|c|c|}
\hline Season & LS mean & $\mathrm{SE}$ & $\mathrm{n}$ & Tukey's HSD \\
\hline 2006-07 & 10.2 & 0.2 & 48 & 2006-07, 2007-08: \\
\hline $2007-08$ & 11.3 & 0.2 & 48 & $p=0.671$ \\
\hline Time period & LS mean & SE & $\mathrm{n}$ & Tukey's HSD \\
\hline Postbreeding & 17.7 & 0.2 & 32 & Post, Winter: $\mathrm{p}=0.007$ \\
\hline Winter & 6.9 & 0.2 & 32 & Winter, Pre: $p=0.467$ \\
\hline Prebreeding & 10.0 & 0.2 & 32 & Pre, Post: $\mathrm{p}=0.141$ \\
\hline Location & LS mean & SE & $\mathrm{n}$ & Tukey's HSD \\
\hline ANI & 9.6 & 0.2 & 48 & \multirow{2}{*}{ ANI, MLH: $p=0.373$} \\
\hline MLH & 12.0 & 0.2 & 48 & \\
\hline Season*Time period & LS mean & $\mathrm{SE}$ & $\mathrm{n}$ & ANOVA \\
\hline 2006-07 Postbreeding & 14.3 & 0.3 & 16 & \multirow{6}{*}{$\mathrm{F}_{2,84}=0.744, \mathrm{p}=0.478$} \\
\hline 2006-07 Winter & 6.3 & 0.3 & 16 & \\
\hline 2006-07 Prebreeding & 11.6 & 0.3 & 16 & \\
\hline 2007-08 Postbreeding & 21.8 & 0.3 & 16 & \\
\hline 2007-08 Winter & 7.6 & 0.3 & 16 & \\
\hline 2007-08 Prebreeding & 8.6 & 0.3 & 16 & \\
\hline Season*Location & LS mean & SE & $\mathrm{n}$ & ANOVA \\
\hline 2006-07 ANI & 10.8 & 0.3 & 24 & \multirow{4}{*}{$\mathrm{F}_{1,84}=1.901, \mathrm{p}=0.172$} \\
\hline 2006-07 MLH & 9.6 & 0.3 & 24 & \\
\hline 2007-08 ANI & 8.6 & 0.3 & 24 & \\
\hline 2007-08 MLH & 14.9 & 0.3 & 24 & \\
\hline Time period*Location & LS mean & $\mathrm{SE}$ & $\mathrm{n}$ & ANOVA \\
\hline Postbreeding ANI & 11.2 & 0.3 & 16 & \multirow{6}{*}{$\mathrm{F}_{2,84}=4.021, \mathrm{p}=0.021$} \\
\hline Postbreeding MLH & 27.4 & 0.3 & 16 & \\
\hline Winter ANI & 5.4 & 0.3 & 16 & \\
\hline Winter MLH & 8.8 & 0.3 & 16 & \\
\hline Prebreeding ANI & 14.4 & 0.3 & 16 & \\
\hline Prebreeding MLH & 6.9 & 0.3 & 16 & \\
\hline Season*Time period*Location & LS mean & SE & $\mathrm{n}$ & ANOVA \\
\hline 2006-07 Postbreeding ANI & 16.7 & 0.5 & 8 & \multirow{12}{*}{$\mathrm{F}_{2,84}=3.362, \mathrm{p}=0.039$} \\
\hline 2006-07 Postbreeding MLH & 12.2 & 0.5 & 8 & \\
\hline 2006-07 Winter ANI & 4.4 & 0.5 & 8 & \\
\hline 2006-07 Winter MLH & 8.9 & 0.5 & 8 & \\
\hline 2006-07 Prebreeding ANI & 16.2 & 0.5 & 8 & \\
\hline 2006-07 Prebreeding MLH & 8.2 & 0.5 & 8 & \\
\hline 2007-08 Postbreeding ANI & 7.5 & 0.5 & 8 & \\
\hline 2007-08 Postbreeding MLH & 60.2 & 0.5 & 8 & \\
\hline 2007-08 Winter ANI & 6.5 & 0.5 & 8 & \\
\hline 2007-08 Winter MLH & 8.8 & 0.5 & 8 & \\
\hline 2007-08 Prebreeding ANI & 12.7 & 0.5 & 8 & \\
\hline 2007-08 Prebreeding MLH & 5.8 & 0.5 & 8 & \\
\hline
\end{tabular}


Shannon-Wiener diversity values and mean number of prey categories consumed by each bird were calculated for combinations of time and space (Table 10). For both nonbreeding seasons combined individual Brandt's Cormorants consumed $2.5(s=1.9)$ prey categories per day $(H=1.67)$. Prey diversity was greater during the 2007-08 nonbreeding season $(H=1.77)$ compared with the 2006-07 nonbreeding season $(H=$ 1.21). For location, overall prey diversity was greatest at Monterey Harbor $(H=1.66)$, followed closely by Moss Landing Harbor $(H=1.59)$ and least at Año Nuevo Island $(H=$ 0.93). On 2 March 2007 during prebreeding at Año Nuevo Island, Brandt's Cormorants specialized on a single prey item, Northern Anchovy. A maximum of 10 prey categories was observed on 10 March 2008 during prebreeding at Monterey Harbor. 
Table 10. Mean $( \pm$ SD) and range for number of prey categories consumed by Brandt's Cormorants and Shannon-Wiener diversity index $(\mathrm{H})$ by time period and location.

\begin{tabular}{clccc}
\hline \hline Time & \multicolumn{1}{c}{ Location } & Mean \pm SD & Range & H \\
\hline $09 / 21 / 06$ & Moss Landing Harbor & $3.5 \pm 2.1$ & $1-7$ & 1.21 \\
$09 / 26 / 06$ & Año Nuevo Island & $2.4 \pm 1.2$ & $1-5$ & 0.61 \\
12/18/06 & Moss Landing Harbor & $2.0 \pm 1.2$ & $1-4$ & 1.22 \\
12/19/06 & Año Nuevo Island & $2.3 \pm 1.7$ & $1-6$ & 2.09 \\
$02 / 22 / 07$ & Moss Landing Harbor & $2.5 \pm 1.8$ & $1-6$ & 1.19 \\
$03 / 02 / 07$ & Año Nuevo Island & $1.0 \pm 0.0$ & $1-1$ & 0.00 \\
$09 / 25 / 07$ & Año Nuevo Island & $2.6 \pm 1.4$ & $1-5$ & 1.88 \\
$09 / 28 / 07$ & Moss Landing Harbor & $5.6 \pm 2.0$ & $2-9$ & 1.45 \\
$10 / 19 / 07$ & Monterey Harbor & $3.3 \pm 1.7$ & $2-7$ & 0.96 \\
$11 / 09 / 07$ & Moss Landing Harbor & $3.1 \pm 2.4$ & $1-9$ & 1.59 \\
$11 / 15 / 07$ & Año Nuevo Island & $1.5 \pm 0.7$ & $1-3$ & 1.48 \\
$11 / 29 / 07$ & Monterey Harbor & $3.1 \pm 2.3$ & $1-9$ & 1.35 \\
$12 / 21 / 07$ & Moss Landing Harbor & $2.9 \pm 2.0$ & $1-7$ & 1.02 \\
$12 / 26 / 07$ & Monterey Harbor & $2.2 \pm 1.7$ & $1-7$ & 1.19 \\
$01 / 17 / 08$ & Año Nuevo Island & $1.4 \pm 0.7$ & $1-3$ & 0.39 \\
$02 / 20 / 08$ & Moss Landing Harbor & $2.3 \pm 1.8$ & $1-6$ & 0.89 \\
$03 / 10 / 08$ & Monterey Harbor & $2.1 \pm 2.3$ & $1-10$ & 0.84 \\
$03 / 24 / 08$ & Año Nuevo Island & $1.1 \pm 0.4$ & $1-2$ & 0.05 \\
$03 / 26 / 08$ & Moss Landing Harbor & $2.5 \pm 1.4$ & $1-5$ & 1.60 \\
$2006-07$ & Año Nuevo Island & $1.9 \pm 1.3$ & $1-6$ & 0.68 \\
$2006-07$ & Moss Landing Harbor & $2.6 \pm 1.8$ & $1-7$ & 1.25 \\
$2007-08$ & Año Nuevo Island & $1.6 \pm 1.0$ & $1-5$ & 1.06 \\
$2007-08$ & Moss Landing Harbor & $3.5 \pm 2.3$ & $1-9$ & 1.66 \\
$2007-08$ & Monterey Harbor & $2.7 \pm 2.0$ & $1-10$ & 1.66 \\
A1l & Año Nuevo Island & $1.7 \pm 1.1$ & $1-6$ & 0.93 \\
All & Moss Landing Harbor & $3.2 \pm 2.2$ & $1-9$ & 1.59 \\
All & Monterey Harbor & $2.7 \pm 2.0$ & $1-10$ & 1.66 \\
$2006-07$ & All & $2.3 \pm 1.6$ & $1-7$ & 1.21 \\
$2007-08$ & All & $2.6 \pm 2.0$ & $1-10$ & 1.77 \\
All & All & $2.5 \pm 1.9$ & $1-10$ & 1.67 \\
\hline & & & &
\end{tabular}

When comparing mean prey diversity among time periods and locations during the 2006-07 nonbreeding season there was not a significant interaction (two-way ANOVA, Model I, $F_{2,48}=2.104, p=0.133$; Table 11); therefore, the main effect hypotheses were examined. The data were normally distributed; however, variances were not equal despite several transformations (Levene's $=9.222, \mathrm{p}<0.001$ ). Only 
anchovy were consumed during prebreeding at Año Nuevo Island, thus mean prey diversity and variance were zero. Even though the assumption of equal variance was not met the patterns in the data were reflected in the ANOVA results, so they were interpreted with caution. Prey diversity among time periods was nearly significant $\left(\mathrm{F}_{2,48}\right.$ $=3.111, \mathrm{p}=0.054)$ with greatest mean prey diversity during winter $(\mathrm{H}=0.384)$ and least during prebreeding $(\mathrm{H}=0.122)$. Mean prey diversity was significantly greater at Moss Landing Harbor compared with Año Nuevo Island $\left(\mathrm{F}_{1,48}=4.195, \mathrm{p}=0.046\right)$. Mean prey diversity was greatest at Moss Landing Harbor during postbreeding $(\mathrm{H}=0.461$; Fig. 8).

Table 11. Two-way ANOVA results comparing prey diversity among time periods and between locations during the 2006-07 nonbreeding season.

\begin{tabular}{lcccc}
\hline \hline Time period & LS mean & SE & $\mathrm{n}$ & ANOVA \\
\hline Postbreeding & 0.285 & 0.1 & 18 & \\
Winter & 0.384 & 0.1 & 18 & $\mathrm{~F}_{2,48}=3.111, \mathrm{p}=0.054$ \\
Prebreeding & 0.122 & 0.1 & 18 & \\
\hline Location & & & & \\
\hline ANI & LS mean & SE & $\mathrm{n}$ & ANOVA \\
MLH & 0.172 & 0.1 & 27 & $\mathrm{~F}_{1,48}=4.195, \mathrm{p}=0.046$ \\
& 0.353 & 0.1 & 27 & \\
\hline Time period*Location & LS mean & SE & $\mathrm{n}$ & ANOVA \\
\hline Postbreeding ANI & 0.130 & 0.1 & 9 & \\
Winter ANI & 0.425 & 0.1 & 9 & \\
Prebreeding ANI & 0.000 & 0.1 & 9 & \multicolumn{1}{c}{$\mathrm{F}_{2,48}=2.104, \mathrm{p}=0.133$} \\
Postbreeding MLH & 0.461 & 0.1 & 9 & \\
Winter MLH & 0.344 & 0.1 & 9 & \\
Prebreeding MLH & 0.259 & 0.1 & 9 & \\
\hline
\end{tabular}



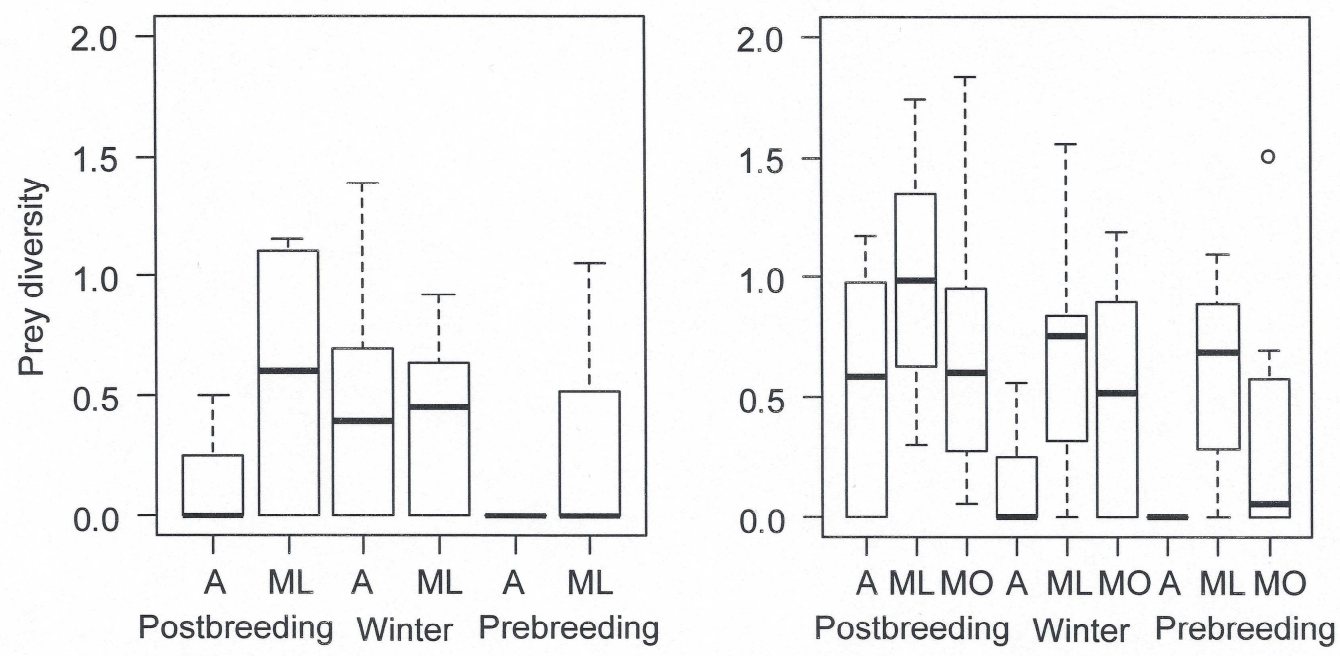

Figure 8. Prey diversity in Brandt's Cormorant diet by time period (postbreeding, winter, and prebreeding) and location (A = Año Nuevo Island, $\mathrm{ML}=$ Moss Landing Harbor, $\mathrm{MO}=$ Monterey Harbor) during the 2006-07 $(\mathrm{n}=9, \mathrm{~N}=54)$ and 2007-08 $(\mathrm{n}=8, \mathrm{~N}=72)$ nonbreeding seasons. Boxplots indicate medians (line), first and third quartiles (bottom and top of box), 95\% confidence intervals (whiskers), and outliers (points).

When comparing mean prey diversity among time periods and locations during the 2007-08 nonbreeding season there was no significant interaction (two-way ANOVA, Model I, $\mathrm{F}_{4,63}=0.252, \mathrm{p}=0.907$; Table 12); therefore, main effect hypotheses were examined. Once again the data were normally distributed, but variances were not equal (Levene's $=5.437, \mathrm{p}<0.001$ ). Like in 2006-07, only anchovy were consumed during prebreeding at Año Nuevo Island in 2007-08, thus mean prey diversity and variance were zero. The ANOVA results reflected the data well, so they were interpreted with caution. There was a significant difference among time periods $\left(\mathrm{F}_{2,63}=6.275, \mathrm{p}=0.003\right)$ and locations $\left(\mathrm{F}_{2,63}=9.723, \mathrm{p}<0.001\right)$. Tukey's HSD multiple comparison tests indicated 
that mean prey diversity was significantly greater during postbreeding compared with winter and prebreeding, and prey diversity was significantly less at Año Nuevo Island compared with Moss Landing Harbor and Monterey Harbor (Table 12; Fig. 8).

Table 12. Two-way ANOVA and multiple comparison test results comparing prey diversity among time periods and locations during the 2007-08 nonbreeding season.

\begin{tabular}{lcccc}
\hline \hline Time period & LS mean & SE & $\mathrm{n}$ & $\begin{array}{c}\text { Tukey's HSD } \\
\mathrm{F}_{2,63}=6.275, \mathrm{p}=0.003\end{array}$ \\
\hline Postbreeding & 0.664 & 0.1 & 24 & Post, Winter: $\mathrm{p}=0.049$ \\
Winter & 0.366 & 0.1 & 24 & Winter, Pre: $\mathrm{p}=0.554$ \\
Prebreeding & 0.254 & 0.1 & 24 & Pre, Post: $\mathrm{p}=0.003$ \\
& & & & \\
\hline Location & LS mean & SE & $\mathrm{n}$ & $\begin{array}{c}\text { Tukey's HSD } \\
\text { ANI }\end{array}$ \\
MLH & 0.177 & 0.1 & 24 & ANI, MLH: $\mathrm{p}<0.001$ \\
MOH & 0.689 & 0.1 & 24 & MLH, MOH: $\mathrm{p}=0.125$ \\
& 0.435 & 0.1 & 24 & MOH, ANI: $\mathrm{p}=0.048$ \\
\hline Time period*Location & LS mean & SE & $\mathrm{n}$ & \\
\hline Postbreeding ANI & 0.465 & 0.1 & 8 & ANOVA \\
Winter ANI & 0.943 & 0.1 & 8 & \\
Prebreeding ANI & 0.619 & 0.1 & 8 & \\
Postbreeding MLH & 0.112 & 0.1 & 8 & \\
Winter MLH & 0.602 & 0.1 & 8 & $\mathrm{~F}_{4,63}=0.252, \mathrm{p}=0.907$ \\
Prebreeding MLH & 0.430 & 0.1 & 8 & \\
Postbreeding MOH & 0.000 & 0.1 & 8 & \\
Winter MOH & 0.548 & 0.1 & 8 & \\
Prebreeding MOH & 0.275 & 0.1 & 8 & \\
\hline
\end{tabular}

When comparing mean prey diversity during 2006-07 and 2007-08 nonbreeding seasons there was a significant interaction between season and time period (multifactorial ANOVA, Model I, $\mathrm{F}_{2,84}=4.145, \mathrm{p}=0.019 ;$ Table 13) and season and location $\left(\mathrm{F}_{1,84}=\right.$ 4.932, $\mathrm{p}=0.029)$; therefore, main effects could not be interpreted. The assumption of 
equal variance was not met. Neither location had a consistent pattern in mean prey diversity between nonbreeding seasons (Fig. 8). Tukey's HSD multiple comparison tests indicated that 2007-08 had significantly greater mean prey diversity compared with 2006$07(\mathrm{p}=0.034$; Fig. 8). In addition, prebreeding mean prey diversity was significantly less than postbreeding $(\mathrm{p}=0.003)$ and moderately less than winter $(\mathrm{p}=0.068)$. Mean prey diversity at Año Nuevo Island was significantly less compared with Moss Landing Harbor $(\mathrm{p}<0.001)$. 
Table 13. Three-way ANOVA and multiple comparison test results comparing prey diversity between $2006-07$ and 2007-08 nonbreeding seasons, among time periods within nonbreeding seasons, and between locations.

\begin{tabular}{|c|c|c|c|c|}
\hline Season & LS mean & SE & $\mathrm{n}$ & $\begin{array}{c}\text { Tukey's HSD } \\
\mathrm{F}_{1,84}=4.663, \mathrm{p}=0.034\end{array}$ \\
\hline 2006-07 & 0.267 & 0.0 & 48 & \multirow{2}{*}{$\begin{array}{c}\text { 2006-07, 2007-08: } \\
p=0.034\end{array}$} \\
\hline $2007-08$ & 0.419 & 0.0 & 48 & \\
\hline Time period & LS mean & SE & $\mathrm{n}$ & $\begin{array}{c}\text { Tukcy's HSD } \\
\mathrm{F}_{2,84}=5.888, \mathrm{p}=0.004 \\
\end{array}$ \\
\hline Postbreeding & 0.474 & 0.0 & 32 & Post, Winter: $\mathrm{p}=0.511$ \\
\hline Winter & 0.374 & 0.0 & 32 & Winter, Pre: $p=0.068$ \\
\hline Prebreeding & 0.190 & 0.0 & 32 & Pre, Post: $\mathrm{p}=0.003$ \\
\hline Location & LS mean & SE & $\mathrm{n}$ & $\begin{array}{c}\text { Tukey's HSD } \\
\mathrm{F}_{1,84}=24.518, \mathrm{p}<0.001 \\
\end{array}$ \\
\hline ANI & 0.179 & 0.0 & 48 & \multirow{2}{*}{ ANI, MLH: $\mathrm{p}<0.001$} \\
\hline MLH & 0.525 & 0.0 & 48 & \\
\hline Season*Time period & LS mean & SE & $\mathrm{n}$ & Tukey's HSD \\
\hline 2006-07 Postbreeding & 0.265 & 0.1 & 16 & \multirow{6}{*}{$\mathrm{F}_{2,84}=4.145, \mathrm{p}=0.019$} \\
\hline 2006-07 Winter & 0.415 & 0.1 & 16 & \\
\hline 2006-07 Prebreeding & 0.138 & 0.1 & 16 & \\
\hline 2007-08 Postbreeding & 0.719 & 0.1 & 16 & \\
\hline 2007-08 Winter & 0.335 & 0.1 & 16 & \\
\hline 2007-08 Prebreeding & 0.244 & 0.1 & 16 & \\
\hline Season*Location & LS mean & SE & $\mathrm{n}$ & Tukey's HSD \\
\hline 2006-07 ANI & 0.181 & 0.1 & 24 & \multirow{4}{*}{$\mathrm{F}_{1,84}=4.932, \mathrm{p}=0.029$} \\
\hline 2006-07 MLH & 0.361 & 0.1 & 24 & \\
\hline 2007-08 ANI & 0.177 & 0.1 & 24 & \\
\hline 2007-08 MLH & 0.709 & 0.1 & 24 & \\
\hline Time*Location & LS mean & $\mathrm{SE}$ & $\mathrm{n}$ & Tukey's HSD \\
\hline Postbreeding ANI & 0.297 & 0.1 & 16 & \multirow{6}{*}{$\mathrm{F}_{2,84}=0.998, \mathrm{p}=0.373$} \\
\hline Postbreeding MLH & 0.677 & 0.1 & 16 & \\
\hline Winter ANI & 0.264 & 0.1 & 16 & \\
\hline Winter MLH & 0.495 & 0.1 & 16 & \\
\hline Prebreeding ANI & 0.000 & 0.1 & 16 & \\
\hline Prebreeding MLH & 0.416 & 0.1 & 16 & \\
\hline Season*Time period*Location & LS mean & $\mathrm{SE}$ & $\mathrm{n}$ & ANOVA \\
\hline 2006-07 Postbreeding ANI & 0.147 & 0.1 & 8 & \multirow{12}{*}{$\mathrm{F}_{2,84}=0.628, \mathrm{p}=0.536$} \\
\hline 2006-07 Postbreeding MLH & 0.395 & 0.1 & 8 & \\
\hline 2006-07 Winter ANI & 0.435 & 0.1 & 8 & \\
\hline 2006-07 Winter MLH & 0.395 & 0.1 & 8 & \\
\hline 2006-07 Prebreeding ANI & 0.000 & 0.1 & 8 & \\
\hline 2006-07 Prebreeding MLH & 0.296 & 0.1 & 8 & \\
\hline 2007-08 Postbreeding ANI & 0.465 & 0.1 & 8 & \\
\hline 2007-08 Postbreeding MLH & 1.016 & 0.1 & 8 & \\
\hline 2007-08 Winter ANI & 0.112 & 0.1 & 8 & \\
\hline 2007-08 Winter MLH & 0.602 & 0.1 & 8 & \\
\hline 2007-08 Prebreeding ANI & 0.000 & 0.1 & 8 & \\
\hline 2007-08 Prebreeding MLH & 0.548 & 0.1 & 8 & \\
\hline
\end{tabular}




\subsection{Prey size}

Few fish otoliths were classified as Grade 1 and suitable for otolith length

measurements to estimate fish length. The average size of the dominant prey, Northern Anchovy, was $8.6 \mathrm{~cm}(s=0.6 \mathrm{~cm}, \mathrm{n}=49)$. Prey size was estimated for 12 species (Table 14). Speckled Sanddab was the smallest prey $(6.4$ to $8.0 \mathrm{~cm})$ and White Croaker (Genyonemus lineatus) the largest (13.8 to $16.2 \mathrm{~cm})$.

Table 14. Sample size of otoliths with minimal erosion, mean ( \pm SD) of otolith lengths $(\mathrm{mm})$, and range of estimated standard lengths $(\mathrm{cm})$ of fishes consumed by Brandt's Cormorants.

\begin{tabular}{lccc}
\hline \hline & & Otolith length (mm) \\
Species & $\mathrm{n}$ & Mean \pm SD & Range of estimated standard lengths (cm) \\
\hline Ammodytes hexapterus & 2 & $2.91 \pm 0.05$ & $13.6-14.0$ \\
Atherinopsis affinis & 4 & $1.97 \pm 0.14$ & $7.4-8.4$ \\
Chilara taylori & 2 & $3.27 \pm 0.09$ & $10.1-10.6$ \\
Citharichthys sordidus & 1 & 3.05 & 12.0 \\
Citharichthys stigmaeus & 7 & $2.47 \pm 0.39$ & $6.4-8.0$ \\
Embiotoca lateralis & 4 & $4.85 \pm 0.08$ & $8.2-8.6$ \\
Engraulis mordax & 49 & $3.40 \pm 0.28$ & $8.0-9.2$ \\
Genyonemus lineatus & 5 & $6.79 \pm 0.80$ & $13.8-16.2$ \\
Leptocottus armatus & 5 & $5.07 \pm 0.87$ & $8.6-13.0$ \\
Parophrys vetulus & 3 & $2.83 \pm 0.19$ & $7.4-8.8$ \\
Porichthys notatus & 2 & $4.26 \pm 0.02$ & $9.3-9.4$ \\
Trachurus symmetricus & 1 & 5.97 & na \\
\hline
\end{tabular}

\subsection{Fine-scale spatiotemporal variation}

Spatiotemporal variation in the multivariate diet composition data $(\% \mathrm{~N})$ for the 19 sampling days (Fig. 9) was examined using nonmetric multidimensional scaling (NMDS, nonmetric fit, $\mathrm{R}^{2}=0.991$, Stress $=0.10 ;$ Fig. 10). The outer coast location, Año Nuevo Island, was distinct from locations within the bay, Moss Landing Harbor and Monterey Harbor. Sampling days were interspersed within the ordination space occupied by each of those locations indicating that differences in diet composition were better determined 
by location than nonbreeding season. Northern Anchovy and perches were associated with diet at Año Nuevo Island. Three flatfishes, Speckled Sanddab, Pacific Sanddab, and English Sole (Parophrys vetulus), were associated with diet at Moss Landing Harbor and Monterey Harbor. Topsmelt was most strongly associated with 19 October 2007 at Monterey Harbor, and to a lesser degree, sampling dates at Moss Landing Harbor. Pacific Sandlance (Ammodytes hexapterus) was associated with 26 March 2008 at Moss Landing Harbor. The prey category for sculpins was centrally located in the ordination indicating similar proportion in the diet throughout the region.

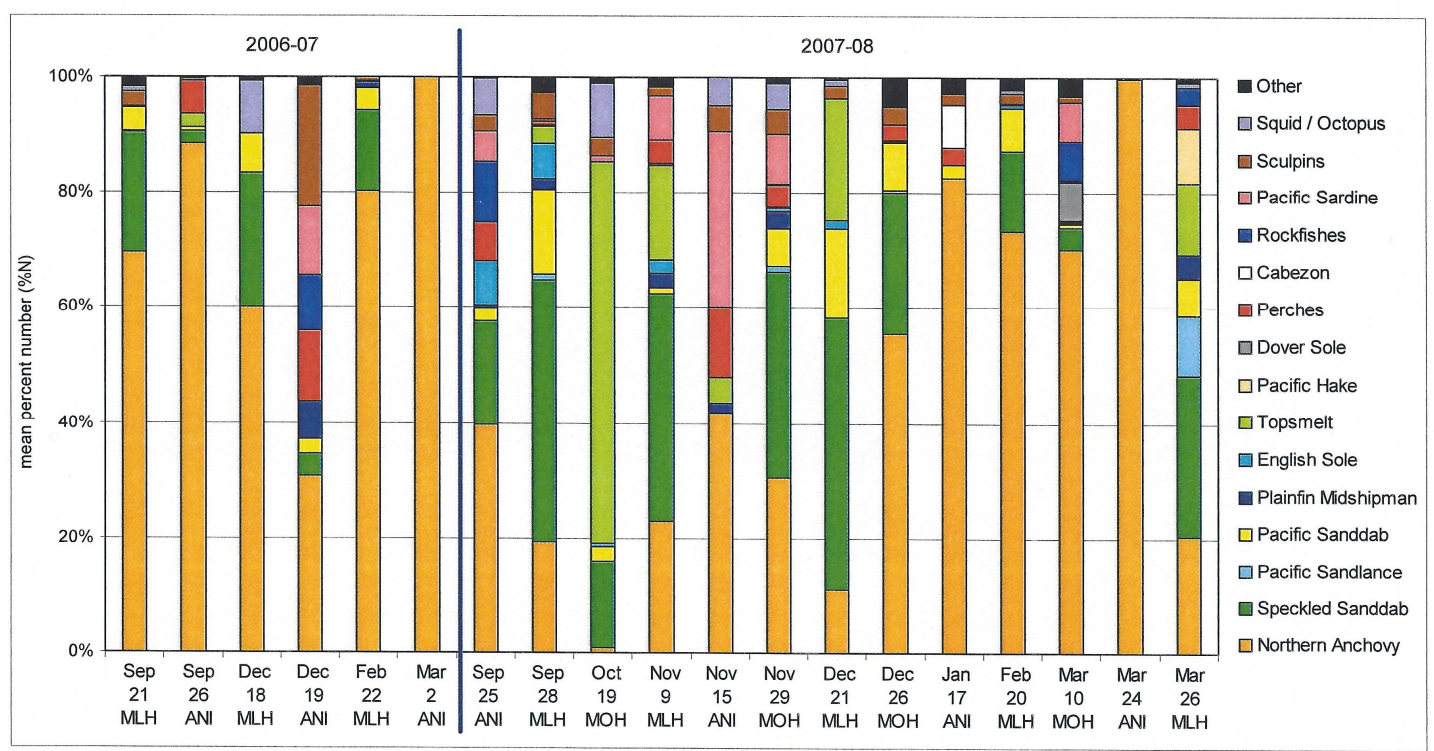

Figure 9. Fine-scale spatiotemporal variation in Brandt's Cormorant diet by mean percent number $(\% \mathrm{~N})$ among 6 sampling days during 2006-07 nonbreeding season and 13 sampling days during 2007-08 nonbreeding season $(\mathrm{n}=15, \mathrm{~N}=285)$. Sampling locations were Año Nuevo Island (ANI), Moss Landing Harbor (MLH), and Monterey Harbor $(\mathrm{MOH})$. Prey species comprising less than $5 \%$ of the diet were combined into category "Other". 


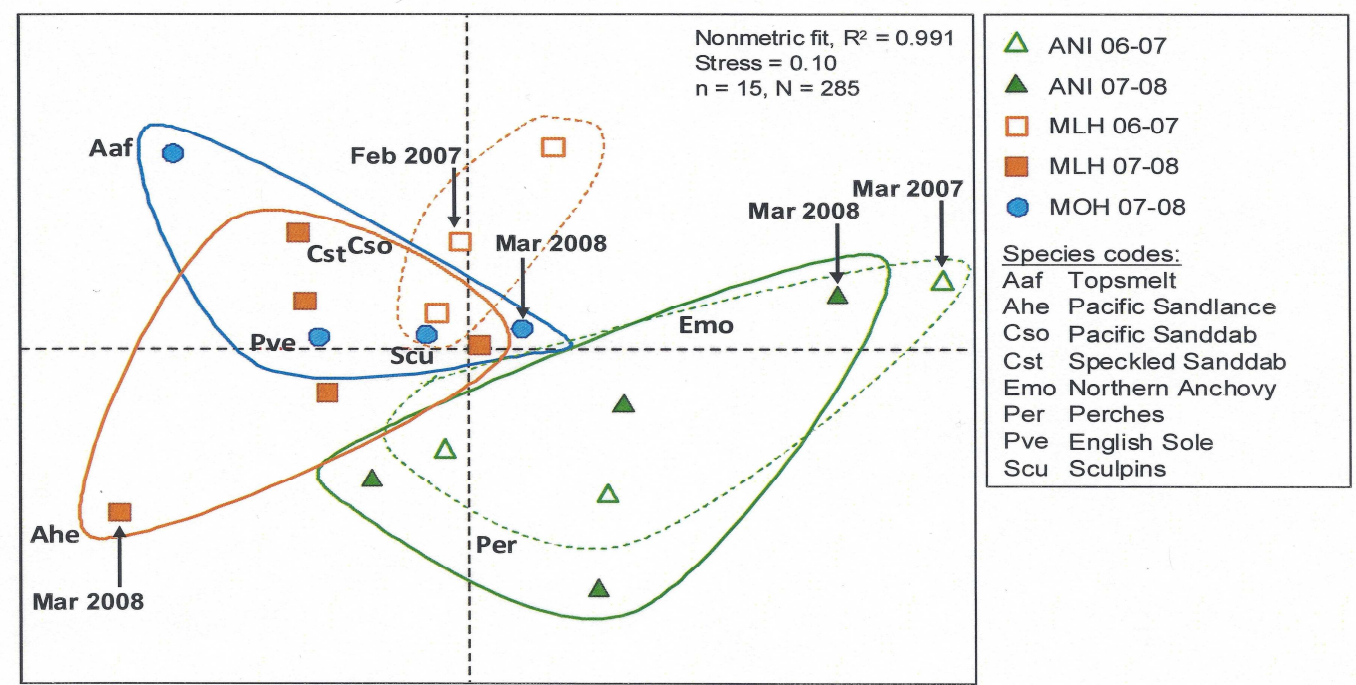

Figure 10. Nonmetric multidimensional scaling ordination comparing spatiotemporal variation in diet composition by percent number $(\% \mathrm{~N})$ among 19 sampling days. Locations sampled were Año Nuevo Island (triangles), Moss Landing Harbor (squares), and Monterey Harbor (circles). Polygons group locations by nonbreeding season (2006-07 dashed and 2007-08 solid). Proximity to the three letter species codes indicates importance in the diet. The last sampling day of cach scason at each location is marked by an arrow with the month and year.

\subsection{Comparing historical and present diet composition}

When the results of this study are placed in context with all available diet data sets for central California a clear pattern of major changes in the diet composition emerges (Fig. 11). During the 1970s and early 1990s the dominant prey in the diet of Brandt's Cormorants was rockfishes at the locations examined, Monterey Bay and Southeast Farallon Island. When the diet was examined again in the early 2000s at Alcatraz Island and in Monterey Bay during this study from 2005 (pilot study) to 200708, Northern Anchovy was a substantial portion of the diet by number and consumption of rockfishes was rare. Throughout the time series there was a decrease in consumption of Pacific Sanddab and increase in Speckled Sanddab. 


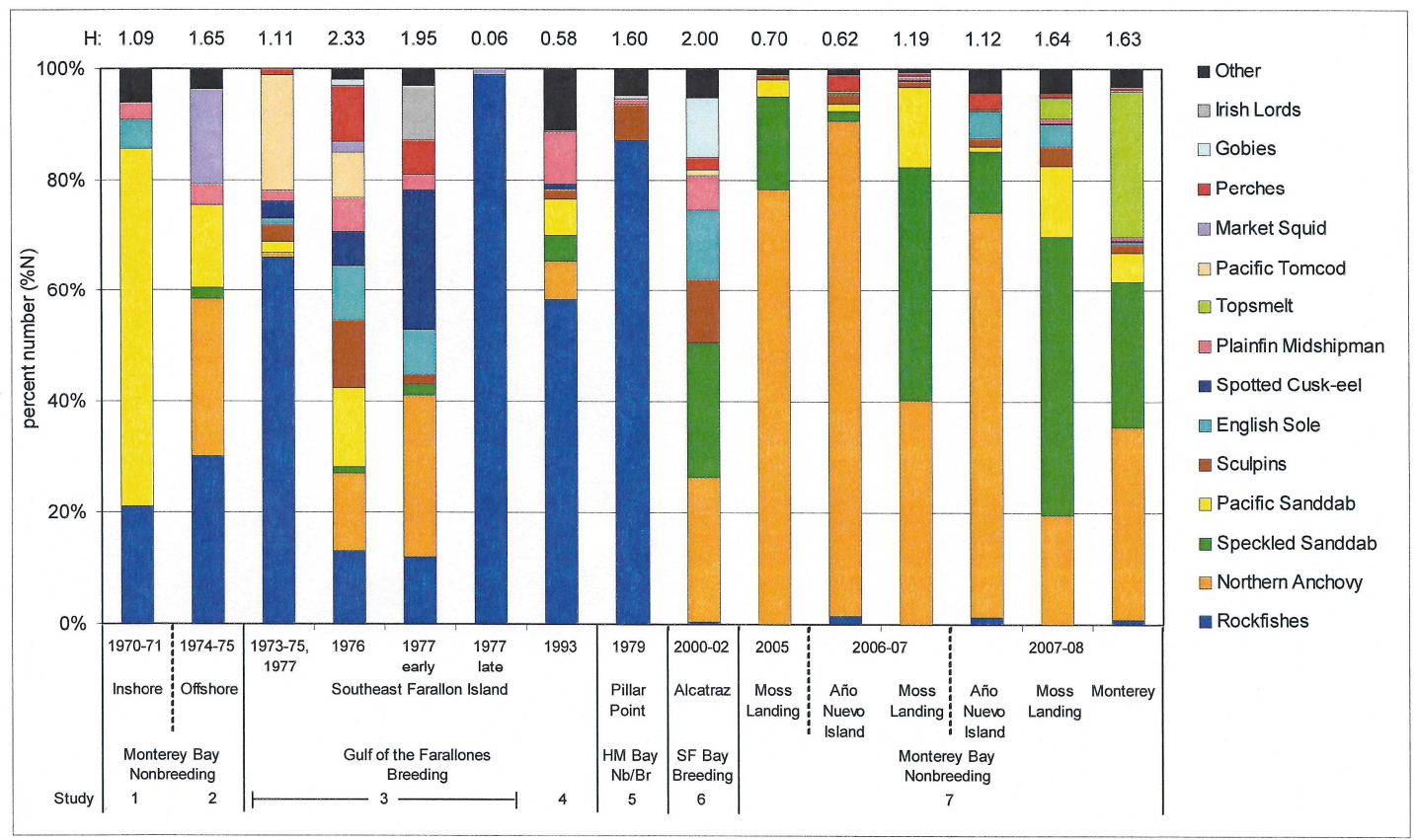

Figure 11. Brandt's Cormorant diet composition by percent number $(\% \mathrm{~N})$ for past studies in central California and this study. Prey species comprising less than 5.0\% were combined into category "Other". Shannon-Wiener diversity index $(\mathrm{H})$ is provided above each bar and time, location, region, and breeding status below each bar. Data are from 1) Talent 1984, 2) Baltz and Morejohn 1977, 3) Ainley et al. 1990, 4) Sydeman et al. 1997, 5) Cutler 1983, 6) Yakich 2005 and 7) this study (including a pilot study in 2005).

The overall multivariate diet composition data $(\% \mathrm{~N})$ for the two historical nonbreeding season diet data sets in Monterey Bay during the 1970s (Baltz and Morejohn 1977, Talent 1984) and the five location and nonbreeding season combinations sampled in this study were compared using nonmetric multidimensional scaling (NMDS, nonmetric fit, $\mathrm{R}^{2}=0.999$, Stress 0.04; Fig. 12). The first NMDS axis separates the historic data from this study by differences in dominant prey: rockfishes were prevalent in the historical data compared with Northern Anchovy in this study. The second NMDS axis further separates by ancillary prey that were consumed in particular nonbreeding seasons and locations. Pacific Sanddab was consumed during both studies during the 1970s whereas Market Squid was only in the diet of birds collected offshore in Monterey 
Bay during the 1974-75 nonbreeding season. During this study, perches occurred in the diet at Año Nuevo Island, Speckled Sanddab was prevalent in the diet at both locations inside Monterey Bay, whereas Topsmelt was mainly observed in the diet at Monterey Harbor. For the two locations sampled during both nonbreeding seasons during this study, Año Nuevo Island and Moss Landing Harbor, diet composition was more similar during the 2007-08 nonbreeding season than the 2006-07 nonbreeding season.

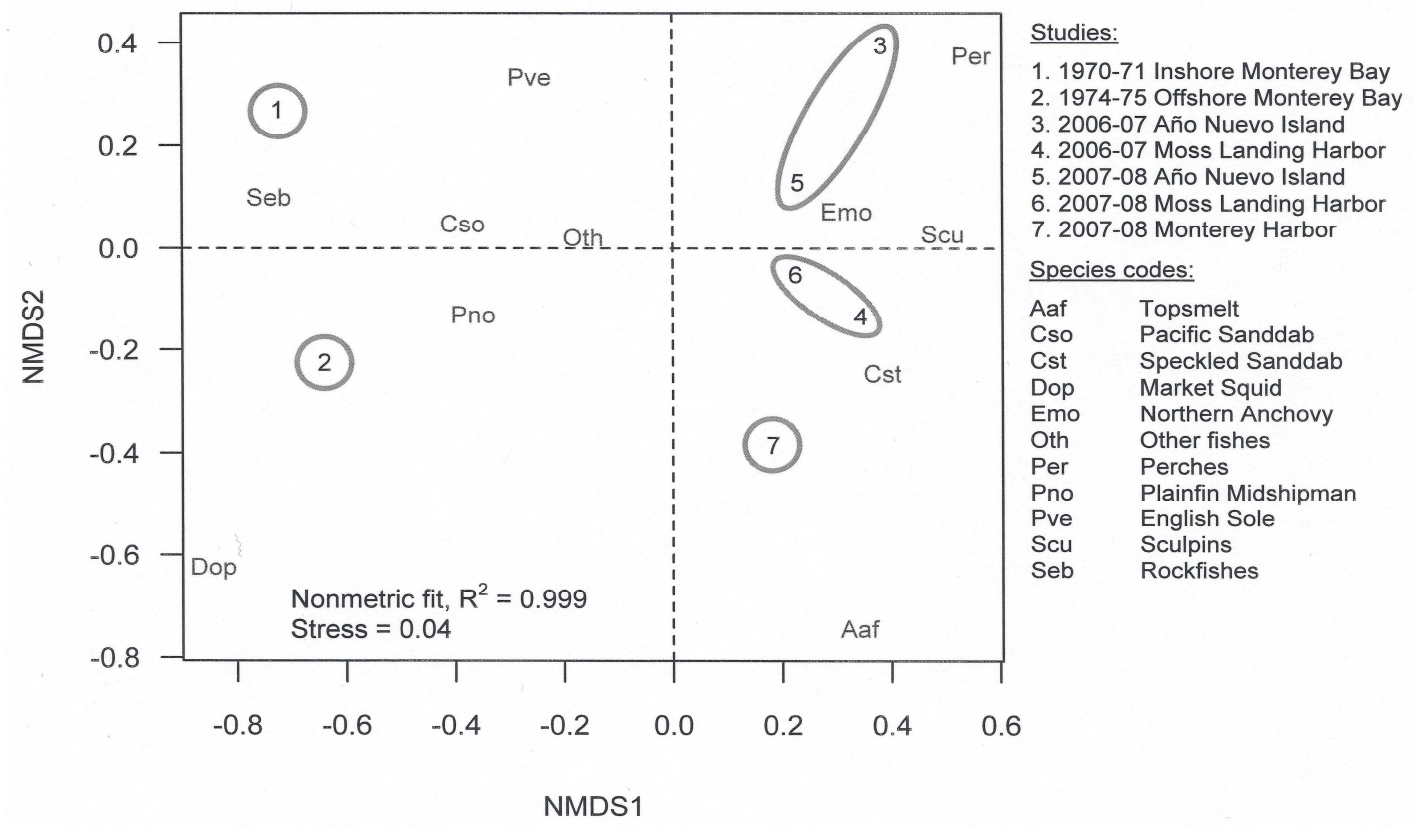

Figure 12. Nonmetric multidimensional scaling ordination comparing overall Brandt's Cormorant diet composition by percent number $(\% \mathrm{~N})$ among studies in the Monterey Bay region. Each study is represented by a number and studies with the same location are circled. Prey species comprising less than $5 \%$ of the diet were combined into category "Other fishes". Proximity to three letter prey species codes indicates importance in the diet. Historic data are from 1) Talent 1984 and 2) Baltz and Morejohn 1977 while the remaining data are from this study. 


\section{DISCUSSION}

In a review of Brandt's Cormorant diet throughout their range Ainley et al. (1981) reported that $59 \%$ of the prey consumed occurred in the water column and $41 \%$ on the bottom. Comparatively, in this study approximately $69 \%$ of prey were taken in the water column. Northern Anchovy, a schooling, coastal pelagic species was $52.6 \%$ of the overall diet by number. During fall and winter Northern Anchovy form large schools from the surface to $55 \mathrm{~m}$ (Love 1996). The size of Northern Anchovy consumed was small, 8.0 to $9.2 \mathrm{~cm}$, indicating they were young-of-the-year or age 1 fishes (Love 1996). The second and fourth most abundant species in the diet were Speckled and Pacific Sanddab, together comprising $21.6 \%$ of the diet by number. Sanddabs consumed were 6 to $12 \mathrm{~cm}$ in length which is between 1 and 2 years of age (Rackowski and Pikitch 1989). Sanddabs occur on the bottom mostly in sandy or sandy mud substrate (Fitch and Lavenberg 1971). The third most abundant prey was Topsmelt, a schooling species that occurs in the upper $9 \mathrm{~m}$ (Love 1996), and they represented $6.5 \%$ of the diet by number. Topsmelt consumed were approximately $8 \mathrm{~cm}$; therefore, they were young-of-the-year (Love 1996). Pacific Sardine, another schooling coastal pelagic species, was the fifth most abundant species with $3.8 \%$ of the overall diet by number. No Pacific Sardine otoliths were suitable for length measurement and subsequent fish length estimation.

Changes in dominant ichthyofauna correlate to changes in sea surface temperature (SST) and the oceanography of Monterey Bay is influenced by interannual and multidecadal forcing in the California Current System (CCS). The CCS is one of the most productive current systems in the world, although annual productivity is variable 
because it is generated by periodic, wind-driven coastal upwelling and influenced by the El Niño Southern Oscillation (ENSO; Glantz and Thompson 1981). The ENSO cycle is rather frequent, approximately every 3 to 7 years, while the Pacific Decadal Oscillation (PDO) operates at a much longer cycle of approximately 50 years (Chavez et al. 2003). The PDO is correlated with a shift between two abundant species in the CCS, occurring approximately every 25 years with basin-scale changes in SST: a warmer regime is associated with Pacific Sardine and a cooler regime is associated with Northern Anchovy. The warmer "sardine regime" is characterized by less nutrients, less primary productivity, more sardines, fewer anchovy, and fewer rockfishes compared with more nutrients, more primary production, fewer sardines, more anchovy, and more rockfishes during the cooler "anchovy regime" (Chavez et al. 2003).

Evaluating historical Brandt's Cormorant diet in the context of PDO regimes explains only some of the prey relative abundances observed. The PDO indicates a cooler water anchovy regime from 1947 to 1976-77, a warmer sardine regime until 1998, and then a regime shift back to cooler water conditions (Chavez et al. 2003; Peterson and Schwing 2003). Studies on Brandt's Cormorant diet during the early-to-mid 1970s were during an anchovy dominated cooler regime, and accordingly, their diet contained appreciable numbers of rockfishes and Northern Anchovy. Two studies were conducted within the warmer regime from 1976-77 to 1998 . In 1979 only a small number of birds were sampled near Half Moon Bay, but a rockfish dominated diet was indicated (Cutler 1983) which is in conflict with expectations. Similarly, in 1993 rockfishes dominated the diet at Southeast Farallon Island (Sydeman et al. 1997) despite warmer water conditions. 
More work is needed to understand if there is a relationship between PDO influenced changes in ichthyofauna and the diet of the Brandt's Cormorant, a nearshore predator.

Annual midwater trawl surveys have been conducted by NOAA Fisheries Service

(Fisheries Ecology Division, SWFSC) in late spring along central California since 1983 and provide data on the relative abundance of pelagic juvenile rockfishes and other juvenile fishes (PaCOOS 2013). The abundance is reported as the standardized anomalies from the log of mean catch rates. There was a positive anomaly for abundance of juvenile rockfishes in the 1993 survey when great numbers of juvenile rockfishes were observed in Brandt's Cormorant diet at Southeast Farallon Island (Sydeman et al. 1997). Brandt's Cormorant diet data collected during this study from 2005 to 2008 was well correlated with the positive anomalies for Northern Anchovy, the negative anomalies for rockfishes and Market Squid, but was not well correlated with the positive anomalies for Pacific Sardine. This indicates that Brandt's Cormorants are consuming prey that is relatively abundant in their environment.

The much shorter time scale of the ENSO may more directly influence Brandt's Cormorant diet because of annual influences on prey recruitment success, especially given the young age classes consumed. Different oceanographic conditions described in CalCOFI (2008) were present before this study, during the two nonbreeding seasons examined in this study, and after the study. Before the pilot study in fall 2005 , there was late onset of spring upwelling and a warm sea surface temperature anomaly. Although this was not an El Niño the anomaly had similar effects. In spring 2006, late onset of upwelling occurred again and a moderate El Niño ensued, but rapidly decayed in early 
2007 when upwelling began early and continued longer than usual. By summer 2007 a moderate-to-strong La Niña had developed with a cooler than average sea surface temperature anomaly of $-2^{\circ} \mathrm{C}$. La Niña conditions peaked during January and February 2008 and then weakened substantially by March 2008. These contrasting oceanographic conditions affected Brandt's Cormorant diet.

When cooler oceanographic conditions occurred during the summer 2007 La Niña prey number was expected to increase. Although this was not observed at a regional scale it was observed within Monterey Bay. The greatest number of prey recorded was during the 2007 postbreeding period at Moss Landing Harbor followed by a continuous decline through prebreeding 2008. Prey number also was great at Monterey Harbor during postbreeding 2007, lesser in winter 2007, but then increased by prebreeding 2008 . Prey number did not increase at Año Nuevo Island until prebreeding 2008. Thus, the overall effect of the 2007 La Niña was greater prey number in Brandt's Cormorant diet within the bay during the 2007-08 nonbreeding season (Moss Landing Harbor, mean = 15.2; Monterey Harbor, mean $=17.0)$ than on the outer coast $($ Año Nuevo Island, mean $=$ 8.6).

These changes in prey number from 2005-06 to 2007-08 were accompanied by changes in diet composition. Overall, Northern Anchovy waned in the diet during 200708. Although diet composition at Año Nuevo Island was dominated by Northern Anchovy during both years, it was less so during 2007-08. Prey diversity did not increase at Año Nuevo Island because the slight decrease of Northern Anchovy was replaced with English Sole and perches, the same prey consumed in 2006-07. At Moss 
Landing Harbor, the loss of Northern Anchovy during 2007-08 was largely replaced with Speckled Sanddab. Other species that increased in the Brandt's Cormorant diet included Pacific Sanddab, and to a lesser degree, a combination of Topsmelt, English Sole, and sculpins. Therefore, prey diversity increased as expected during cooler oceanographic conditions but only at Moss Landing Harbor. Monterey Harbor was sampled only during the colder-water year and overall diet composition was approximately equal amounts of Northern Anchovy, Speckled Sanddab, and Topsmelt.

The expectation that diversity would increase during winter relative to postbreeding or prebreeding was observed only in part of this study. The expected pattern was observed during the 2006-07 nonbreeding season with greater diversity during winter at Año Nuevo Island and Moss Landing Harbor. However, during the 2007-08 nonbreeding season prey diversity did not increase during winter at any location, but it did increase earlier during postbreeding 2007, likely reflecting the more productive conditions during the La Niña. The mean winter diversity values were similar for 2006$07(H=0.384)$ and 2007-08 $(H=0.366)$. The anomalous La Niña event seems to have altered typical timing. During normal oceanographic conditions the pattern of greater diversity during winter likely prevails.

There is some evidence that another major fluctuation in the dominant prey of Brandt's Cormorants began at the end of this study. Northern Anchovy were common in the diet of Brandt's Cormorants at Southeast Farallon Island from 2002 to 2008 but were less frequently observed from 2009 to 2011 (Warzybok and Bradley 2011). A large dieoff event of Brandt's Cormorants occurred during the 2009 breeding season in central 
California, and because disease tests were negative, starvation was considered the most likely cause (H. Nevins, unpublished data). This is consistent with the loss of Northern Anchovy as a prey resource. That Brandt's Cormorants did not respond to the loss of Northern Anchovy by consuming other prey species possibly represents time required to transition from foraging mostly as a specialist back to foraging mostly as a generalist.

Increased abundance of juvenile rockfishes was observed in the 2012 and 2013 midwater trawl surveys in central California (PaCOOS 2013); therefore, it is likely that abundance of juvenile rockfishes also increased in Brandt's Cormorant diet in the Monterey Bay region. Another possible indication of diet composition returning to coldwater affiliated species came with opportunistic samples collected at Moss Landing Harbor in March 2010 that contained numerous juvenile Market Squid, far in excess of anything observed from 2005 to 2008.

This study is the first to examine fine-scale spatiotemporal diet variation in Brandt's Cormorants. The sampling scheme detected different location responses to the same oceanographic stimulus. This study demonstrated the importance of periodic sampling at multiple locations within a region to detect changes in the diet of this opportunistic generalist.

Seabirds have increasingly been studied as indicators of the marine ecosystem (Piatt et al. 2007). Northern Anchovy, rockfishes, and Market Squid that are common in Brandt's Cormorant diet are important to many other predators in the CCS (Morejohn et al. 1978, Ainley et al. 1990). As a piscivorous generalist, the Brandt's Cormorant is a good candidate for a nearshore indicator species because their distribution includes the 
full extent of the CCS. This would allow large areas to concurrently be examined thereby providing insight into the geographic extent of prey fluctuations. 


\section{LITERATURE CITED}

Ainley DG, Anderson DW, Kelly PR. 1981. Feeding ecology of marine cormorants in southwestern North America. Condor 83:120-131.

Ainley DG, Strong CS, Penniman TM, Boekelheide RJ. 1990. The feeding ecology of Farallon seabirds. In: Ainley DG, Boekelheide, RJ, editors. Seabirds of the Farallon Islands: ecology, structure, and dynamics of an upwelling system community. Stanford University Press, Stanford, California. p. 51-127.

Ainley DG, Sydeman WJ, Norton J. 1995. Upper trophic level predators indicate interannual negative and positive anomalies in the California Current food web. Mar. Ecol. Prog. Ser. 118:69-79.

Allis EP. 1909. The anatomy of the mail-cheeked fishes. Zoologica (Stuttg.) 22:1-219.

Amundsen PA, Gabler HM, Staldvik FJ. 1996. A new approach to graphical analysis of feeding strategy from stomach contents data-modification of the Costello (1990) method. J. Fish Biol. 48:607-614.

Ancel A, Horning M, Kooyman GL. 1997. Prey ingestion revealed by esophagus and stomach temperature recordings in cormorants. J. Exp. Biol. 200:149-154.

Baltz DM, Morejohn GV. 1977. Food habits and niche overlap of seabirds wintering on Monterey Bay, California. Auk 94: 526-543.

Barrett RT, Rov N, Loen J, Montevecchi WA. 1990. Diet of shags Phalacrocorax aristotelis and cormorants $P$. carbo in Norway and possible implications for gadoid stock recruitment. Mar. Ecol. Prog. Ser. 66:205-218.

Barrett RT, Camphuysen KCJ, Anker-Nilssen T, Chardine JW, Furness RW, Garthe S, Hüppop O, Leopold MF, Montevecchi WA, Veit RR. 2007. Diet studies of seabirds: a review and recommendations. ICES J. Mar. Sci. 64:1675-1691.

Barry JP, Yoklavich MM, Cailliet GM, Ambrose DA, Antrim BS. 1996. Trophic ecology of the dominant fishes in Elkhorn Slough, California, 1974-1980. Estuaries 19:115-138.

Bechaver CA, McChesney GJ, Capitolo PJ, Golightly RT, Fuller AR, Carter HR, Parker MW, Rhoades SJ. 2013. Breeding population trends of Brandt's Cormorants in the Monterey Bay Area, California, 2001-2011. Unpublished report, Humboldt State University, Arcata, California and U.S. Fish and Wildlife Service, San Francisco Bay National Wildlife Refuge Complex, Fremont, California. 43 pp. 
Bizzarro JJ, Robinson HJ, Rinewalt CS, Ebert DA. 2007. Comparative feeding ecology of four sympatric skate species off central California, USA. Environ. Biol. Fishes 80:197-220.

Boekelheide RJ, Ainley DG. 1989. Age, resource availability, and breeding effort in Brandt's Cormorant. Auk 106:389-401.

Boekelheide RJ, Ainley DG, Morrell SH, Lewis TJ. 1990. Brandt's cormorant. In: Ainley DG, Boekelheide RJ, editors. Seabirds of the Farallon Islands: ecology, dynamics and structure of an upwelling-system community. Stanford, California: Stanford University Press. p 163-194.

Breaker LC, Broenkow WW. 1994. The circulation of Monterey Bay and related processes. Oceanography and Marine Biology, An Annual Review 32:1-64.

Briggs KT, Tyler WB, Lewis DB, Carlson DR. 1987. Bird communities at sea off California. Stud. Avian Biol. 11:1-74.

Brown SC, Bizzarro JJ, Cailliet GM, Ebert DA. 2012. Breaking with tradition: redefining measures for diet description with a case study of the Aleutian skate Bathyraja aleutica (Gilbert 1896) Environ. Biol. Fishes 95:3-20.

Cailliet GM, Karpov KA, Ambrose DA. 1979. Pelagic assemblages as determined from purse seine and large midwater trawl catches in Monterey Bay and their affinities with the market squid, Loligo opalescens. California Cooperative Oceanic Fisheries Investigations Reports 20:21-30.

[CalCOFI] California Cooperative Oceanic Fisheries Investigations. 2008. The State of the California Current, 2007-2008: La Nina Conditions and Their Effects on the Ecosystem. CalCOFI Report 49:39-76.

Cannon DY. 1987. Marine fish osteology - a manual for Archaeologists. Archaeology Press, Simon Fraser University, Burnaby, B.C., 36 p.

Carter HR, McChesney GJ, Jaques DL, Strong CS, Parker MW, Takekawa JE, Jory DL, Whitworth DL. 1992. Breeding populations of seabirds in California, 1989-1991. Vols 1 and 2. Unpublished draft final report, U.S. Fish and Wildlife Service, Northern Prairie Wildlife Research Center, Dixon, California.

Casaux RJ, Favero M, Barrera-Oro ER, Silva P. 1995. Feeding trial on an Imperial Cormorant Phalacrocorax atriceps: preliminary results on fish intake and otolith digestion. Mar. Ornithol. 23:101-106. 
[CDFG] California Department of Fish and Game (CA). 2009 Apr. Annual Fisheries Forum, Fisheries Report. [Internet]. Monterey (CA): Marine Region. [cited 2010 January 9]. Available from: https://nrm.dfg.ca.gov/FileHandler.ashx?DocumentID=36309\&inline=true.

Chapman 1944aThe osteology of the Pacific deep-bodied anchovy, Anchoa compressa. J. Morphol. 74(2):311-329.

Chapman 1944b The Comparative Osteology of the Herring-like Fishes (Clupeidae) of California. Calif. Fish Game 30(1):6-21.

Chavez FP, Ryan J, Lluch-Cota SE, Niquen C M. 2003. From anchovies to sardines and back: multidecadal change in the Pacific Ocean. Science 299:217-221.

Costello MJ. 1990. Predator feeding strategy and prey importance: a new graphical analysis. J. Fish Biol. 36:261-263.

Cutler SM. 1983. A comparative study of the head morphology and feeding ecology of three species of cormorants [master's thesis]. [San Francisco (CA)]: San Francisco State University.

Dirksen S, Boudewign TJ, Noordhuis R, Marteijn EL. 1995. Cormorants Phalacrocorax carbo sinensis in shallow eutrophic freshwater lakes: prey choice and fish consumption in the non-breeding period and effects of large-scale fish. Ardea $83: 167-184$.

Duffy DC, Laurenson LJB. 1983. Pellets of Cape Cormorants as indicators of diet. Condor 85:305-307.

Duffy D, Jackson S. 1986. Diet studies of seabirds: a review of methods. Colonial Waterbirds 9:1-17.

Ferry LA, Cailliet GM. Sample size and data analysis: are we characterizing and comparing diet properly? In: McKinlay D, Shearer K (eds) Gutshop '96, 1996. Feeding ecology and nutrition in fish symposium proceedings. San Francisco State University, pp 71-80.

Fish M, Messineo J, Hieb K. 2011. 2010 Bay study fishes annual status and trends report for the San Francisco Estuary. California: Interagency Ecological Program. IEP Fall-Winter 2011 Newsletter 24(4):1-27. Available from: www.water.ca.gov/iep/products/newsletter.cfm

Fitch JE, Lavenberg RJ. 1971. Marine food and game fishes of California. University of California Press, USA. 179 p. 
Glantz M, Thompson JD. 1981. Resource management and environmental uncertainty: lessons from coastal upwelling fisheries. John Wiley and Sons, New York. 491 p.

Gobalet KW, Schulz PD, Wake TA, Siefkin N. 2004. Archaeological perspectives on Native American fisheries of California, with emphasis on steelhead and salmon. Trans. Am. Fish. Soc. 133:801-833.

Hansel HC, Duke SD, Lofy PT, Gray GA. 1988. Use of diagnostic bones to identify and estimate original lengths of ingested prey fishes. Trans. Am. Fish. Soc. 177:55-62.

Harris MP, Wanless S. 1993. The diet of shags Phalacrocorax aristotelis during the chick-rearing period assessed by three methods. Bird Study 40:135-139.

Harvey JT, Loughlin TR, Perez MA, Oxman DS. 2000. Relationship between fish size and otolith length for 63 species of fishes from the Eastern North Pacific Ocean. Seattle (WA): National Oceanographic and Atmospheric Administration (US). Report No.: NMFS 150. 36 p. Available from: NMFS, Seattle, WA.

Hayashi K, Kim JN. 1999. Revision of the East Asian species of Crangon (Decapoda: Caridea: Crangonidae). Crustacean Research 28:62-103.

Hebshi A. 1998. Foraging site preferences of Brandt's Cormorants off the Santa Cruz, California, Coast. Colonial Waterbirds 21(2):245-250.

Henkel LA. 2006. Effect of water clarity on the distribution of marine birds in nearshore waters of Monterey Bay, California. J. Field Ornithol. 77(2):151-156.

Henkel LA, Harvey JT. 2006. Potential prey resources for Marbled Murrelets in Central California. Calif. Fish Game 92(4):191-206.

Hubbs CL, Kelly AL, Limbaugh C. 1970. Diversity in feeding by Brandt's Cormorant near San Diego. Calif. Fish Game 56(3):156-165.

Hyslop EJ. 1980. Stomach content analysis - a review of methods and their applications. J. Fish Biol. 17:411-429.

Iverson LK, Pinkas L. 1971. A pictorial guide to beaks of certain eastern Pacific cephalopods. Calif. Dep. Fish Game Fish Bull. 152:83-105.

Jobling M, Breiby A. 1986. The use and abuse of fish otoliths in studies of feeding habits of marine piscivores. Sarsia 71:265-274.

Johnstone IG, Harris MP, Wanless S, Graves JA. 1990. The usefulness of pellets for assessing the diet of adult shags Phalacrocorax aristotelis. Bird Study 37:5-11. 
Jordán R. 1959. El fenomeno de las regurgitaciones en el Guanay (Phalacrocorax bougainvillii L.) y un metodo para estimar la ingestion diaria. Bol. Cia. Adm. Guano 35(4):23-40.

Lance MM, Orr AJ, Riemer SD, Weise MJ, Laake JL. 2001. AFSC Processed Report 2001-2004: pinniped food habits and prey identification protocol. Seattle (WA): National Oceanographic and Atmospheric Administration (US). Available from: NMFS, Seattle, WA.

Legendre P, Legendre L. 1998. Numerical ecology. Elsevier. New York. 853 p.

Liem KF. 1986. The pharyngeal jaw apparatus of the Embiotocidae (Teleostei): a functional and evolutionary perspective. Copeia 1986(2):311-323.

Love M. 1996. Probably more than you want to know about the fishes of the Pacific Coast. Really Big Press. Santa Barbara. 381 p.

McInnis RR, Broenkow WW. 1978. Correlations between squid catches and oceanographic conditions in Monterey Bay, California. Calif. Dep. Fish Game Fish Bull. 169:161-170.

Miller DJ, Lea RN. 1972. Guide to the coastal marine fishes of California. Calif. Dep. Fish Game Fish Bull. 157. 235 p.

Mills KL, Laidig T, Ralston S, Sydeman WJ. 2007. Diets of top predators indicate pelagic juvenile rockfish (Sebastes spp.) abundance in the California Current System. Fish. Oceanogr. 16:273-283.

Morejohn GV, Harvey JT, Krasnow LT. 1978. The importance of Loligo opalescens in the food web of marine vertebrates in Monterey Bay, California. Calif. Dep. Fish Game Fish Bull. 169:67-98.

Owre OT. 1967. Adaptations for locomotion and feeding in the Anhinga and the Doublecrested Cormorant. Am. Ornithol. Union, Monogr. No. 6.

[PaCOOS] Pacific Coast Ocean Observing Systems (CA). 2013 Apr-Jun. Climatic and Ecological Conditions in the California Current LME for April to June 2013: 6(2). [Internet]. [cited 2013 August 6]. Available from: http://pacoos.org/QuarterlyUpdate_Climatic/vol6_Q2Year2013.pdf.

Paduan JD, Rosenfeld LK. 1996. Remotely sensed surface currents in Monterey Bay from shore-based HF radar (Coastal Ocean Dynamics Application Radar). J. Geophys. Res. 101(C9):20669-20686. 
Page LM, Espinosa-Pérez H, Findley LT, Gilbert CR, Lea RN, Mandrak NE, Mayden RL, and Nelson JS. 2013. Common and scientific names of fishes from the United States, Canada, and Mexico. 7th ed. Bethesda: American Fisheries Society, Special Publication 34. Part I, Scientific name, occurrence, and accepted common name; $\mathrm{p}$ 47-191.

Pennington JT, Chavez FP. 2000. Seasonal fluctuations of temperature, salinity, nitrate, chlorophyll and primary production at station H3/M1 over 1989-1996 in Monterey Bay, California. Deep-Sea Res II 47:947-973.

Peterson WT, Schwing FB. 2003. A new climate regime in northeast pacific ecosystems. Geophys. Res. Letters 30(17):1-4.

Piatt JF, Sydeman WJ, Weise F. 2007. Introduction: a modern role for seabirds as indicators. Mar. Ecol. Prog. Ser. 352:199-204.

Rackowski JP, Pikitch EK. 1989. Species profiles: life histories and environmental requirements of coastal fishes and invertebrates (Pacific Southwest). Pacific and speckled sanddabs. U.S. Fish and Wildlife Service. Biol. Rep. 82 (11.107). U.S. Army Corps of Engineers, TR EL-82-4. 18 pp.

Ribak G, Weihs D, Arad Z. 2004. How do cormorants counter buoyancy during submerged swimming? J. Exp. Biol. 207:2101-2114.

Rosenfeld LK, Schwing FB, Garfield N, Tracy DE. 1994. Bifurcated flow from an upwelling center: a cold water source for Monterey Bay. Cont. Shelf Res. 14:931964.

Sapoznikow A, Quintana F, Kuba L. 2009. Low seasonal variation in the diet of Rock Shags (Phalacrocorax magellanicus) at a Patagonian colony in Argentina. Emu 109:35-39.

Schmitt WL. 1921. The marine decapod crustacean of California. University of California Press, Berkeley, CA.

Shannon CE. 1948. A mathematical theory of communication. Bell System Technical Journal 27:379-423.

Shepard FP. 1973. Submarine geology. New York: Harper and Row. 517 p.

Spear LB. 1993. Dynamics and effect of Western Gulls feeding in a colony of guillemots and Brandt's Cormorants. J. Anim. Ecol. 62(3):399-414. 
Sydeman WJ, Hobson KA, Pyle P, McLaren EB. 1997. Trophic relationships among seabirds in central California: combined stable isotope and conventional dietary approach. Condor 99:327-336.

Sydeman WJ, Hester MM, Thayer JA, Gress F, Martin P, Buffa J. 2001. Climate change, reproductive performance and diet composition of marine birds in the southern California Current system, 1969-1997. Progress in Oceanography 49:309-329.

Talent L. 1984. Food habits of wintering Brandt's Cormorants. Wilson Bull. 96(1):130134.

Tollit DJ, Steward MJ, Thompson PM, Pierce GJ, Santos MB, Hughes S. 1997. Species and size differences in the digestion of otoliths and beaks: implications for estimates of pinniped diet composition. Can. J. Fish. Aquat. Sci. 54:105-119.

Tollit DJ, Wong M, Winship AJ, Rosen DAS, Trites AW. 2003. Quantifying errors associated with using prey skeletal structures from fecal samples to determine the diet of Steller's Sea Lion (Eumetopias jubatus). Mar. Mamm. Sci. 19(4):724-744.

Voslamber B, Platteeuw M, Van Eerden MR. 1988. Solitary foraging in sand pits by breeding cormorants Phalacrocorax carbo sinensis: does specialized knowledge about fishing sites and fish behaviour pay off? Ardea 83:213-222.

Wallace EAH, Wallace GE. 1998. Brandt's Cormorant. In: The Birds of North America, No. 362. Poole A, Gill F, editors. Ithaca (NY). Cornell Laboratory of Ornithology and the Academy of Natural Science, Cornell. p. 1-32.

Warzybok PM, Bradley RW. 2011. Status of seabirds on Southeast Farallon Island during the 2011 breeding season. Unpublished report to the US Fish and Wildlife Service. PRBO Conservation Science, Petaluma, California. PRBO Contribution Number 1836.

Yakich JD. 2005. A dietary analysis of Brandt's Cormorants (Phalacrocorax penicillatus) breeding in central San Francisco Bay [master's thesis]. [San Francisco (CA)]: San Francisco State University.

Yoklavich MM, Cailliet GM, Barry JP, Ambrose DA, Antrim BS. 1991. Temporal and spatial patterns in diversity of fish assemblages in Elkhorn Slough, California. Estuaries 14(4):465-480.

Zijlstra M, Van Eerden MR. 1995. Pellet production and the use of otoliths in determining the diet of cormorants Phalacrocorax carbo sinensis: trials with captive birds. Ardea 83:123-131. 